Stephanie Agnes Díaz Huamán

\title{
eficácia de Um novo Protocolo de tratamento ENDODÔNTICO EM SESSÃO ÚNICA. ESTUDO RADIOGRÁFICO E histopatológico Em Dentes de CÃes Com lesões Periapicais INDUZIDAS.
}

Dissertação apresentada à Faculdade de Odontologia de Ribeirão Preto da Universidade de São Paulo, para obtenção do título de Mestre em Ciências.

Programa: Odontopediatria

Área de Concentração: Odontopediatria

Orientador: Profa. Dra. Andiara De Rossi

Ribeirão Preto 


\section{AUTORIZO A REPRODUÇÃO E DIVULGAÇÃO TOTAL OU PARCIAL DESTE TRABALHO, POR QUALQUER MEIO CONVENCIONAL OU ELETRÔNICO, PARA FINS DE ESTUDO E PESQUISA, DESDE QUE CITADA A FONTE.}

\section{FICHA CATALOGRÁFICA}

Huamán, Stephanie Agnes Díaz

Eficácia de um novo protocolo de tratamento endodôntico em sessão única. Estudo radiográfico e histopatológico em dentes de cães com lesões periapicais induzidas.

Huamán, Stephanie Agnes Díaz, Ribeirão Preto, 2018.

83 p.: il.; $30 \mathrm{~cm}$

Dissertação de Mestrado apresentada à Faculdade de Odontologia de Ribeirão Preto da Universidade de São Paulo. Área de concentração: Odontopediatria.

Orientador: De Rossi, Andiara

1. Medicação intracanal 2. Hidróxido de cálcio 3. Periodontite apical. 
FOLHA DE APROVAÇÃo

HUAMÁN, STEPHANIE AGNES DÍAZ. Eficácia de um novo protocolo de tratamento endodôntico em sessão única. Estudo radiográfico e histopatológico em dentes de cães com lesões periapicais induzidas.

Dissertação apresentada à Faculdade de Odontologia de Ribeirão Preto da Universidade de São Paulo, para a obtenção do Título de Mestre em Ciências.

Área de Concentração: Odontopediatria

Aprovado em:

\section{BANCA EXAMINADORA}

Prof. Dr.

Instituição:

Julgamento: Assinatura:

Prof. Dr.

Instituição:

Julgamento: Assinatura:

Prof. Dr.

Instituição:

Julgamento: Assinatura: 



\section{STEPHANIE AGNES DÍAZ HUAMÁN}

Nascimento

Filiação

2007-2012

2016-2018
23 de julho de 1990, Lima, Perú

Alecxy Díaz Sandoval

Nelly Raquel Huamán de Díaz

Graduação em Odontologia

Faculdade de Odontologia da Universidade Peruana

Cayetano Heredia, Lima, Perú

Mestrado em Ciências

Área de Concentração: Odontopediatria

Faculdade de Odontologia de Ribeirão Preto da

Universidade de São Paulo - FORP/USP, SP, Brasil 

À Deus, que me dá a vida e as forças

para ir à luta todos os dias.

Aos meus avós que estão me cuidando sempre, Salomón, Ali e Lidia. Anjos que Deus me deu para nunca me sentir sozinha. Amo vocês até o céu. 

Aos meus pais, Nelly e Alecxy. Sus esfuerzos y su fuerza, me hicieron la persona que soy. Ustedes siempre fueron mi tranquilidad entre tantas dificultades. Los amo incansablemente.

Ao meu noivo, Jorge. No hubo día en el que no me hicieras falta y te agradeceré por el resto de nuestros días que me hayas esperado. Estos dos años los caminamos juntos a la distancia y este triunfo es de los dos. Te amo.

À minha irmã, Ximena, mi pequeña acompañante, gracias por darme un poco de tu alegría cuando necesitaba más de ustedes.

Aos meus irmãos, Rodrigo e Samantha, Ustedes son esa chispa preciosa que le faltaba a nuestra familia. Gracias por existir.

À minha avó, Ynés, obrigada por tanto amor vovozinha.

A todos os meus familiares e amigos, sem sua alegria e calor, eu não me sentiria tão forte quanto me sinto hoje, muito obrigada. 
À Faculdade de Odontologia de Ribeirão Preto da Universidade de São Paulo,

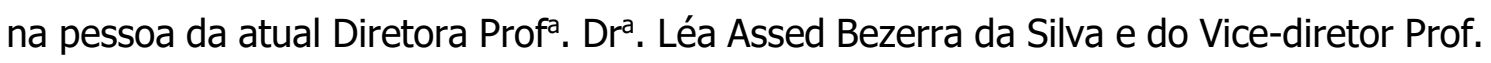
Dr. Arthur Belém Novaes Júnior e à Coordenação do Curso de Pós-Graduação em Odontopediatria da Faculdade de Odontologia de Ribeirão Preto da Universidade de São Paulo, na pessoa da coordenadora, Prof ${ }^{\mathrm{a}}$. Dra ${ }^{\mathrm{a}}$. Alexandra Mussolino de Queiroz.

À minha orientadora Profa. Dra. Andiara De Rossi, por ter confiado em mim para desenvolver esse projeto. Obrigada pelas horas de dedicação, por esclarecer minhas dúvidas e sempre me ensinar alguma coisa nova. Obrigada por não ter deixado que a falta de conhecimentos ou o idioma signifiquem um obstáculo no meu aprendizado. A minha experiencia na FORP foi proveitosa pela sua excelente orientação, com sua ajuda descobri minha paixão pela pesquisa e sempre estarei agradecida.

Aos professores do departamento da Clínica Infantil da Faculdade de Odontologia de Ribeirão Preto da Universidade de São Paulo pelo aprendizado diário, novas experiencias e pela permanente vontade de ensinar. Uma menção especial para os professores doutores Francisco Wanderley Paula-Silva, Kranya Victoria Díaz-Serrano e para as cirurgiãs-dentistas do departamento da Clínica Infantil Dra. Carol Paes Torres Montavani e Dra. Marília Pacífico Lucisano pela ajuda incondicional na clínica de Trauma e Bruxismo, pelos conhecimentos transmitidos e experiências vividas.

A todo o pessoal técnico envolvido no desenvolvimento do presente trabalho, Marco Antonio dos Santos e Nilza Letícia Magalhães. Sem sua paciência e dedicação, esse trabalho não teria acontecido, obrigada pela ajuda.

Aos pós-graduandos em Odontopediatria da Faculdade de Odontologia de Ribeirão Preto da Universidade de São Paulo, obrigada pela convivência, trocas de experiências, por todo apoio e amizade.

A todos os funcionários da Faculdade de Odontologia de Ribeirão Preto da Universidade de São Paulo, especialmente aos funcionários do Departamento de Clínica Infantil, pela atenção e por toda ajuda durante esse período. 
Ao Conselho Nacional de Pesquisa e Tecnologia pela bolsa PEC PG concedida, foi uma surpresa que mudou a minha vida.

Aos meus amigos em Ribeirão Preto, Silvia Yacarini, Guido Marañon e Jennyfer Aldana, entre outros. Os cafés da manhã, almoços e jantares juntos sempre ficarão na minha mente e no meu coração. Vocês se tornaram minha amada família em Ribeirão Preto, uma benção quando mais precisava e uma alegria importante na minha vida, obrigada por tudo. Los quiero mucho.

À Dona Eva Ferreira Carvalho, pelo seu carinho e alegria sempre, definitivamente a senhora é o anjinho dos meninos latinos e a nossa amada avó. Obrigada sempre. 



\section{RESUMO}

Huamán, SD. Eficácia de um novo protocolo de tratamento endodôntico em sessão única. Estudo radiográfico e histopatológico em dentes de cães com lesões periapicais induzidas. Ribeirão Preto, 2018. 83 p. Dissertação [mestrado]. Faculdade de Odontologia de Ribeirão Preto, Universidade de São Paulo.

Em dentes com lesão periapical, o tratamento endodôntico em duas sessões, com aplicação de curativo de demora, apresenta maior sucesso no combate à infecção intra e extrarradicular, proporcionando reparo dos tecidos apicais e periapicais. No entanto, o tratamento em sessão única vem sendo recomendado em função de reduzir custos e sessões de tratamento, apesar da sua comprovada ineficácia na erradicação dos micro-organismos e taxa de sucesso inferior. Diante da necessidade de reduzir o tempo clínico e favorecer a reparação tecidual, a aplicação de medicação com pasta à base de hidróxido de cálcio apenas na região apical e periapical, obtida por meio de seu extravasamento via canal radicular, seguida pela obturação na mesma sessão poderia constituir uma nova opção de tratamento. Com este objetivo, um total de 60 raízes de pré-molares de cão com rizogênese completa e lesões periapicais experimentalmente induzidas, foram aleatoriamente divididos em 3 grupos submetidos a diferentes protocolos de tratamento endodôntico: 1) novo protocolo em sessão única, com aplicação de pasta à base de hidróxido de cálcio na região apical e periapical antes da obturação; 2) tratamento convencional em duas sessões, com utilização de curativo de demora com pasta à base de hidróxido de cálcio durante 14 dias; 3) tratamento convencional em sessão única. Para avaliação da resposta tecidual, os dentes foram avaliados radiograficamente e histopatologicamente, 120 dias após o tratamento endodôntico com a eutanásia dos animais. Os espécimes foram processados histotecnicamente, corados com HE e avaliados com microscopia de luz convencional e de fluorescência. Os resultados obtidos foram analisados estatisticamente utilizando os testes qui-quadrado, Fisher, Anova e pós teste de Tukey, com nível de significância de $5 \%$ em todos os testes. De 
acordo com os resultados radiográficos, os dentes tratados com o novo protocolo apresentaram redução na área radiolúcida periapical semelhante aos dentes tratados em duas sessões $(p<0,05)$ e ambos foram superiores ao tratamento em sessão única $(p<0,001)$. Os resultados histopatológicos mostraram que a realização do novo protocolo proporcionou a reparação das estruturas periapicais e apicais em evolução, com presença suave de fibras colágenas jovens, poucos vasos sanguíneos neoformados, infiltrado inflamatório suave a moderado, deposição de cemento celular ou reinserção de fibras colágenas em lacunas de reabsorção paralisadas e selamento apical completo em 18,2\% dos casos. Os dentes tratados em duas sessões apresentaram estágio de reparação mais avançado, com a mesma espessura do espaço do ligamento periodontal, porém com presença de fibras colágenas mais maduras, mais vasos sanguíneos jovens, infiltrado inflamatório suave, deposição de cemento celular em lacunas de reabsorção paralisadas e processo de selamento apical completo em 30,8\% dos casos. Nos dentes tratados em sessão única, observou-se persistência da lesão periapical com presença de infiltrado inflamatório moderado a severo, presença de reabsorção ativa dos tecidos mineralizados, ligamento periodontal aumentado e ausência de selamento apical em $100 \%$ dos casos, sendo estatisticamente diferente dos grupos anteriores em todos parâmetros avaliados $(p<0,001)$. Foi possível concluir que o novo protocolo de tratamento em única sessão promoveu a reparação tecidual, porém em estágio menos avançado que o tratamento em duas sessões com utilização de curativo de demora.

Palavras-chave: Medicação intra-canal, hidróxido de cálcio, periodontite apical. 


\section{ABSTRACT}

Huamán, SD. Novel single-session endodontic treatment protocol using intracanal medication prior obturation. Ribeirão Preto, 2018. 83 p.

Dissertação [mestrado]. Faculdade de Odontologia de Ribeirão Preto, Universidade de São Paulo.

In apical periodontitis, two-session endodontic treatment using intracanal medication between appointments presents a higher success rate at intra and extra radicular disinfection giving a better apical and periapical tissues' repair. Meanwhile, one-session treatment has been highly recommended due to fewer operative time and expenses, even having its proven inefficacy in root canal system cleansing and lower success rate in apical and periapical tissues repair after endodontic treatment. To reduce operative sessions and costs while promoting tissue repair and patient's comfort, we proposed a novel protocol in endodontic treatment of apical periodontitis with extravasation of a $\mathrm{CH}$-based paste into periapical region and obturation performed in a single session. A total of 60 mature dog's premolar teeth with experimentally induced periapical lesions were randomly classified into 3 groups: 1) Novel protocol with extravasation of $\mathrm{CH}$-based paste into apical and periapical region and obturation performed in a single session, 2) Two-session treatment with $\mathrm{CH}$-based intracanal medication in 14 days-interval sessions and 3) Single-session treatment. Radiographs were taken at day 0 and day 120 . After 120 days, animals were killed, maxillae and mandibles were histotechnically processed and stained with HE and analyzed under conventional and fluorescent microscopy. Descriptive, semi quantitative and quantitative histopathological of histopathological parameters was performed. Results were statistically analyzed using chi square test, Fisher test, Kruskal-Wallis test, Dunn's post-test, Anova one-way and Tukey's test, with a 5\% level of significance. According to radiographic analysis, teeth treated with the novel protocol had a percent rate reduction similar to teeth with a two-session treatment $(p<0,05)$, and both groups were superior to single-session group. Histopathological analysis' results showed that performing endodontic treatment 
using the novel protocol provided repair in process of the apical and periapical structures, with few young collagen fibers, few neoformed blood vessels, mild to moderate inflammatory infiltrate, cellular cement deposition or collagen fibers reinsertion at inactive resorption lacunae and complete apical sealing in 18,2\% of teeth. Teeth treated in two sessions had a more advanced repair with a similar periodontal ligament thickness, however, with more mature collagen fibers, neoformed blood vessels, mild inflammatory infiltrate, cellular cement deposition at inactive resorption lacunae and complete apical sealing in $30,8 \%$ of specimens. In teeth treated in a single session, we observed persistence of the periapical lesion with a moderate to severe inflammatory infiltrate, active resorption of the mineralized tissues, increased periodontal ligament thickness and absence of apical sealing in $100 \%$ of specimens, being statistically different to the other groups in all evaluated parameters $(p<0,001)$. We conclude that the proposed novel protocol promoted an early repair of apical and periapical tissues, yet, less developed than two-session treatment with utilization of intracanal medicament in between sessions.

Key Words. Intracanal medicament, calcium hydroxide, apical periodontitis. 


\section{SUMÁRIO}

1. INTRODUÇÃO....................................................................... 19

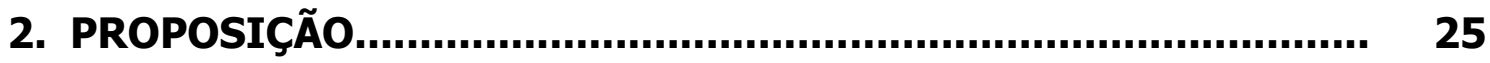

3. MATERIAL E MÉTODOS.................................................... 29

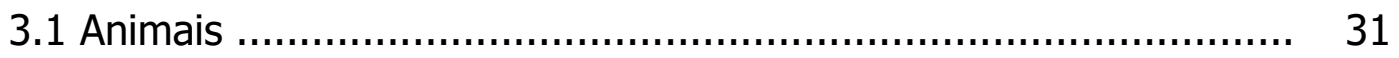

3.2 Procedimentos operatórios................................................. 31

3.3 Análise radiográfica......................................................... 36

3.4 Processamento histotécnico e análise histopatológica .................. 37

3.5 Forma de análise de resultados............................................... 39

4. RESULTADOS................................................................. 41

4.1 Análise radiográfica .......................................................... 43

4.2 Análise histopatológica ...................................................... 44

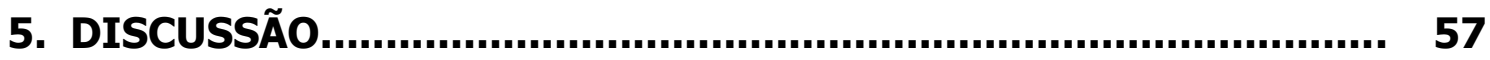

6. CONCLUSÃO......................................................................... 65

REFERÊNCIAS.......................................................................... 69

ANEXO 

1. INTRODUCÃO 

O tratamento de canais radiculares de dentes portadores de necrose pulpar e lesão periapical permanece um assunto controverso e de grande interesse entre profissionais e pesquisadores (Signoretti et al., 2011; ParedesVieyra e Enriquez, 2012; Vera et al., 2012; Ricucci et al., 2015; Donyavi et al., 2016; Manfredi et al., 2016; Moreira et al., 2017). O índice de sucesso nesse tratamento, quando avaliado não apenas do ponto de vista clínico e radiográfico, mas também microbiológico e histopatológico, ainda é inferior ao dos dentes sem lesão periapical (Sjogren et al., 1997; Wong et al., 2015; Pirani et al., 2018). 0 sucesso reduzido e as falhas no tratamento vêm sendo principalmente associadas à persistência de infecção intra e extra radicular (Nair et al., 1990; Nair et al., 1999; Siqueira e Roças, 2004; Siqueira et al., 2011; Cardoso et al., 2016; Siqueira et al., 2016; Pereira et al., 2017), que resultam na manutenção da lesão inflamatória e da reabsorção tecidual, impedindo a ocorrência do processo de reparo.

O objetivo principal do tratamento endodôntico ideal é promover a erradicação da infecção polimicrobiana do sistema de canais radiculares e região periapical, pois esta constitui o agente etiológico principal da doença periapical (Kakehashi et al., 1965; Tronstad, 1992; Siqueira et al., 2011; Nobrega et al., 2016). Atualmente sabe-se que a infecção em dentes decíduos e permanentes com necrose pulpar e lesão periapical encontra-se localizada não apenas na luz do canal radicular e túbulos dentinários, mas também em todo o sistema de canais radiculares e áreas externas da superfície radicular (biofilme periapical), que são inacessíveis ao preparo biomecânico (Leonardo et al., 2002; Leonardo et al., 2007; Rocha et al., 2008; Tanomaru et al., 2008; Ricucci et al., 2018). Além de ação antimicrobiana, o tratamento deve promover inativação das endotoxinas bacterianas ou lipopolissacarídeos (LPS) encontradas na parede celular de bactérias anaeróbias Gram-negativas, que são prevalentes nos dentes portadores de lesão periapical (Rietschel e Brade, 1992; Tani-Ishii et al., 1994; Assed et al., 1996; Leonardo et al., 2000; Leonardo et al., 2004; Siqueira et al., 2007; Adl et al., 2015). As endotoxinas também não são inativadas pelo preparo biomecânico convencional e sua persistência, principalmente em microorganismos presentes em erosões cementárias, protegidos pelo biofilme 
bacteriano, são as principais causas que justificam o fracasso da terapia endodôntica (Byström e Sundqvist, 1981; Molander et al., 1998; Nair et al., 1999; Leonardo et al., 2002; Rocha et al., 2008; Cardoso et al., 2016; Siqueira et al., 2016; Pereira et al., 2017).

Apesar dos recentes avanços tecnológicos, o combate à infecção endodôntica intra e extra radicular e a inativação do LPS bacteriano são possíveis somente com o uso de substâncias antibacterianas utilizadas topicamente entre sessões, denominadas curativo de demora (Bystrom et al., 1985; Haasapalo e Orstavik, 1987; Silva et al., 2014). O hidróxido de cálcio é um pó branco, alcalino (pH 12,8), solúvel em água (Staehle et al., 1997; Estrela e Holland, 2003) tem sido a medicação mais estudada, discutida e empregada com esta finalidade, devido às suas excelentes propriedades como ação antibacteriana (Georgopoulou et al., 1993; Leonardo et al., 1995; Assed et al., 1996; Leonardo et al., 2000), anti-exsudativa (Heithersay, 1970; Allard et al., 1987), indutora da formação de tecido mineralizado por ativação da fosfatase alcalina e da síntese de colágeno (Holland, Souza, Mello et al., 1979; Schroder, 1985; Leonardo et al., 2006; Da Silva, L. A. et al., 2008), biocompatibilidade (Nelson Filho et al., 1999; Leonardo et al., 2006; Zarei et al., 2016), propriedade de dissolução dos tecidos necróticos (Hasselgren et al., 1988; Andersen et al., 1992) e de promoção de hidrólise do LPS bacteriano "in vitro" (Safavi e Nichols, 1994; Barthel et al., 1997; Tanomaru et al., 2003; Oliveira et al., 2005; Oliveira et al., 2007) e "in vivo" (Nelson-Filho et al., 2002; Silva et al., 2002; Adl et al., 2015). Para estas ações o curativo de demora deve permanecer por um período mínimo de 14 dias, o que exige a realização de duas sessões de tratamento (Spångberg, 2001; Leonardo et al., 2006).

A filosofia de tratamento em duas sessões é embasada no fato da eliminação da infecção não ser alcançada quando se realiza o tratamento em uma única sessão, uma vez que não é possível controlar a infecção localizada além do canal radicular principal (campo de ação do endodontista) sem o uso de um curativo de demora antimicrobiano entre as sessões. No entanto, por meio de estudos restritos à avaliações clínicas e radiográficas (Pirani et al., 2015), alguns autores acreditam que o sucesso é semelhante quando se realiza 0 
tratamento endodôntico em sessão única (sem o uso de curativo de demora) ou em duas sessões, empregando o hidróxido de cálcio como curativo de demora (Sathorn et al., 2005; Molander et al., 2007; Penesis et al., 2008). O tratamento de dentes portadores de necrose pulpar e lesão periapical crônica em sessão única ainda é preconizado por quase $70 \%$ dos endodontistas (Whitten et al., 1996; Savani et al., 2014) e 70\% das instituições de ensino de graduação nos EUA (Qualtrough et al., 1999). Em um estudo recente, avaliações clínicas e radiográficas sugerem sucesso de $90 \%$ no reparo de lesões periapicais tratadas em sessão única, quando apresentam diâmetro menor que $5 \mathrm{~mm}$ (Eyuboglu et al., 2017).

O tratamento de dentes portadores de lesão periapical em sessão única é defendida por aqueles que acreditam que a técnica oferece a vantagem de ser mais aceita pelo paciente e profissional em relação ao tempo e custo (Sathorn et al., 2005; Wong, Zhang et al., 2015; Bharuka e Mandroli, 2016). Para alguns autores essa técnica de tratamento também apresenta menor chance de agudecimento e causa menos dor pós-operatória (Walton e Fouad, 1992; Imura e Zuolo, 1995; Albashaireh e Alnegrish, 1998; Soares e César, 2001; Fonzar et al., 2017). No entanto estas justificativas também são questionáveis, sendo encontrados estudos que sugerem que a dor pós-operatória e o risco de agudecimento são maiores na sessão única enquanto a maioria dos estudos não revela diferenças na dor pós-operatória em tratamentos realizados em uma ou duas sessões (Direnzo et al., 2002; Wang et al., 2010; Singh e Garg, 2012; Rao et al., 2014; Patil et al., 2016).

Diferentes técnicas e materiais vêm sendo sugeridos pela literatura visando promover o efetivo controle da microbiota envolvida na lesão periapical, inativação da endotoxina bacteriana, paralização da reabsorção e indução da formação de tecido mineralizado em uma sessão de tratamento. Dentre estes destaca-se o formocresol (Coser e Giro, 2010) como medicamento entre sessões, que fornece o controle da infecção mediante estimulação da necrose superficial dos tecidos conjuntivos e inativação bacteriana, e o iodofórmio (Dotto et al., 2006) que atualmente vem sendo desacreditados pelas suas propriedades tóxicas e potencialmente cancerígenas; as pastas antibióticas como a pasta TRIMIX ou 
tri-antibiótica (Adl et al., 2012; Adl et al., 2014; Pai et al., 2014; Lakhani et al., 2017); a associação do hidróxido de cálcio com agentes antimicrobianos como a clorexidina (De Rossi et al., 2005; Silva et al., 2008; Silva et al., 2009; Donyavi et al., 2016); soluções irrigadoras e medicamentos intracanais baseados em agentes naturais como a epicalogatequina-3-galato, derivado do chá verde (Horiba et al., 1991; Lee et al., 2009; Ferreira, 2013; Ramezanali et al., 2016) e o própolis (Rezende et al., 2008; Awawdeh et al., 2009; Madhubala et al., 2011; Del Carpio-Perochena et al., 2017); utilização de novos sistemas de irrigação por pressão negativa como o EndoVac (Pawar et al., 2012; Cohenca et al., 2013; Cohenca et al., 2015) ou passiva como o EndoActivator (Huffaker et al., 2010; Paiva et al., 2013; Rico-Romano et al., 2016); terapia fotodinâmica (Archilla et al., 2012; Silva et al., 2012; Borsatto et al., 2016; Hidalgo et al., 2016; Rabello et al., 2017) ou cimentos à base de MTA (Gomes-Filho et al., 2013; Jafari et al., 2016; Jafari et al., 2017). No entanto, até o momento nenhum novo material ou técnica proporcionou $100 \%$ de sucesso clínico, radiográfico, histomicrobiológico e histopatológico no reparo das lesões periapicais tratadas em sessão única, sendo ainda fundamental a utilização de medicação entre sessões com pastas à base de hidróxido de cálcio (Massara, 2012).

Diante da necessidade de reduzir custos e tempo clínico e favorecer o conforto do paciente e a reparação tecidual, a aplicação de medicação apenas na região periapical, obtido pelo extravasamento do mesmo via canal radicular, seguido pela obturação dos canais na mesma sessão poderia constituir uma nova opção de tratamento. Esse procedimento permitiria associar ambas filosofias, somando o benefício do curativo de demora, que seria mantido por tempo prolongado até sua reabsorção pelo organismo, à vantagem do tratamento em sessão única. No entanto, há a necessidade de se realizar estudos clínicos, radiográficos e histopatológicos para avaliar e comprovar a sua eficácia no reparo de lesões periapicais, quando comparada as técnicas convencionais de tratamento em uma ou múltiplas sessões, atualmente utilizadas. 
2. PROPOSIÇÃO 

Avaliar a resposta dos tecidos apicais e periapicais de dentes de cães com periodontite apical induzida experimentalmente, após a realização de um novo protocolo de tratamento endodôntico em sessão única com aplicação de pasta à base de hidróxido de cálcio na região apical e periapical, comparado aos tratamentos convencionais, realizados em única ou dupla sessão, por meio de estudo radiográfico e histopatológico. 

3. MATERIAL E METODOS 



\subsection{Animais}

Inicialmente o presente estudo foi submetido à apreciação pela Comissão de Ética no uso de Animais da Faculdade de Odontologia de Ribeirão Preto da Universidade de São Paulo (CEUA/FORP-USP), tendo sido aprovado (processo 2014.1.703.58.9 - Anexo A). Os cuidados com o bem-estar dos animais de experimentação seguiram as Normas e Princípios Éticos Adotados pela CEUA/FORP-USP e as Resoluções Normativas do Conselho Nacional de Controle de Experimentação Animal (CONCEA), regulamentadas pela Constituição Federal Brasileira na Lei no 11.794 de 8 de outubro 2008.

Foram incluídos na pesquisa 3 cães da raça Beagle, de ambos os gêneros, com 12 meses de idade e peso médio de $15 \mathrm{Kg}$. Durante todo o período de experimento os animais permaneceram no Biotério II da FORP-USP, sob cuidados de um veterinário e equipe especializada. A dieta dos animais incluiu ração e água à vontade. Antes do início dos experimentos, o preparo dos animais foi realizado por meio da aplicação de vermífugos (Drontal Puppy - Bayer - São Paulo - SP - Brasil), na dosagem de 1 comprimido a cada $10 \mathrm{~kg}$ de peso do animal, vitaminas (Glicopan Pet - Vetnil Indústria e Comércio de Produtos Veterinários Ltda. - Louveira - Brasil), vacina anti-rábica (Rai-Vac I - Fort Dodge - Campinas SP - Brasil) e Duramune (Fort Dodge) em 3 doses, com 3 semanas de intervalo entre cada aplicação. Caso apresentassem gengivite e/ou cálculo gengival, os animais foram submetidos à profilaxia, raspagem, alisamento e polimento dentário, seguidas da aplicação de digluconato de clorexidina a 0,12\% (Periogard - Colgate - Palmolive, Indústria Ltda., Brasil).

\subsection{Procedimentos Operatórios}

O protocolo experimental foi realizado com base nas normas da International Organization for Standardization (ISO) n 7405:2008, com exceção dos períodos experimentais preconizados (28 e 90 dias). No presente estudo, 3 cães foram acompanhados por um único período de 120 dias, visando restringir o número de animais ao mínimo indispensável para obtenção de resultados conclusivos, em atendimento à Lei Brasileira no 11.794 (Art. 11, §4') e às recomendações da CEUA/FORP-USP. 
Foram utilizados os $2^{\text {os }}$ e $3^{\text {os }}$ pré-molares superiores e os $2^{\text {os }}, 3^{\text {os }}$ e $4^{\text {os }}$ prémolares inferiores permanentes, totalizando 30 dentes (60 raízes). Todos os dentes apresentavam-se hígidos, com 2 raízes e 2 canais radiculares separados (mesial e distal), retos e com rizogênese completa.

Os dentes foram distribuídos em 3 grupos, sendo um experimental e dois controles, de acordo com o protocolo de tratamento endodôntico utilizado. No Grupo Experimental (14 dentes, $n=28$ raízes) foi realizado o novo protocolo de tratamento, com ligeiro extravasamento de pasta à base de hidróxido de cálcio (Calen ${ }^{\circledR}$ - S.S. White Artigos Dentários Ltda. - Rio de Janeiro - RJ - Brasil) na região periapical seguido de obturação dos canais radiculares na mesma sessão. Nos Grupos Controle, positivo e negativo ( 8 dentes, $n=16$ raízes por grupo), foram realizadas as técnicas de tratamento em duas sessões com uso de curativo demora com pasta à base de hidróxido de cálcio (Calen ${ }^{\circledR}$ ) com intervalo de 14 dias entre sessões ou obturação em sessão única (Tabela 1). Para que todas as variáveis fossem testadas em um mesmo animal, e em diferentes quadrantes, cada hemiarco recebeu uma técnica, em sistema de rodízio distribuído ao acaso.

Tabela 1. Distribuição dos Grupos experimental e controles de acordo com o protocolo de tratamento e número de dentes utilizados

\begin{tabular}{clc} 
Grupo & \multicolumn{1}{c}{ Protocolo de tratamento } & \multicolumn{1}{c}{$\begin{array}{c}\text { Número de dentes } \\
\text { (raízes) }\end{array}$} \\
\hline Experimental & $\begin{array}{l}\text { Extravasamento de curativo com pasta à base } \\
\text { de hidróxido de cálcio (Calen }{ }^{\oplus} \text { ), seguido de } \\
\text { obturação dos canais radiculares na mesma } \\
\text { sessão }\end{array}$ & 14 dentes (28 raízes) \\
\hline $\begin{array}{c}\text { (Novo protocolo) } \\
\text { (Duas sessões) }\end{array}$ & $\begin{array}{l}\text { Curativo com pasta à base de hidróxido de (Calen ) por 14 dias, seguido de } \\
\text { obturação dos canais radiculares }\end{array}$ & 8 dentes (16 raízes) \\
\hline $\begin{array}{c}\text { Controle negativo } \\
\text { (Sessão Única) }\end{array}$ & $\begin{array}{l}\text { Obturação dos canais radiculares na mesma } \\
\text { sessão sem uso de curativo de demora }\end{array}$ & 8 dentes (16 raízes) \\
\hline
\end{tabular}

Para a realização dos procedimentos operatórios foi realizada a anestesia inalatória dos animais sob os cuidados de um médico veterinário. Na fase de tranquilização, os animais foram pré-anestesiados, por meio de injeção por via 
endovenosa de acepromazina (Acepran 0,2\% - Vetnil Indústria e Comércio de Produtos Veterinários Ltda. - Louveira - SP - Brasil), na dosagem de 0,11 mg/kg de peso, 15 minutos antes do ato operatório. Na fase de indução foi aplicado o zolazepam (Zoletil 50 Virbac do Brasil - São Paulo - SP - Brasil), na dosagem de $3 \mathrm{mg} / \mathrm{kg}$ de peso, por via endovenosa, para posterior passagem da sonda endotraqueal, necessária para a realização da anestesia inalatória. Após a intubação com sonda endotraqueal, a fase de manutenção da anestesia foi realizada com isofluorano (Abbott Laborat. do Brasil Ltda. - Rio de Janeiro - RJ Brasil), na concentração de 1,5 a 2,5\% juntamente com oxigênio, utilizando o aparelho para anestesia inalatória (Takaoka KT-20 - Biocom Tecnologia - São Paulo - SP - Brasil), até indução do efeito. Durante todo ato operatório, os animais foram mantidos com solução isotônica de cloreto de sódio a 0,9\% (Glicolabor Indústria Farmacêutica Ltda. - Ribeirão Preto - SP - Brasil), sob monitoramento cardiorrespiratório realizado com auxílio de oxímetro de pulso veterinário (Edan ZEH100B - System Biomédica - Yucatan - México). Após a realização dos procedimentos operatórios, os animais receberam analgésico (Cloridrato de Tramadol - Medley S/A - Campinas -Brasil) na dosagem de $3 \mathrm{mg} / \mathrm{kg}$ de peso, por via endovenosa, a cada 12 horas, durante 2 dias.

O exame radiográfico periapical dos dentes foi realizado com filmes periapicais $n^{\circ} 2$, ultra-rápidos (Eastman Kodak Company - Rochester - NY - EUA), pela técnica da bissetriz. Foi utilizado um posicionador radiográfico específico para cães (Cordeiro et al., 1995) e aparelho de raios-X odontológico (Heliodent Siemens - NY - EUA), com 60 kVp e 10 mA e tempo de exposição de 1 segundo. As radiografias foram reveladas em câmara escura pelo método tempo/temperatura.

Todo o instrumental utilizado nos procedimentos operatórios foi esterilizado em autoclave a $121^{\circ} \mathrm{C}$, por 20 minutos (Souza-Gugelmin et al., 2005) e os procedimentos operatórios foram realizados por um único cirurgião-dentista com ampla experiência em experimentação animal. Após a realização de profilaxia e antissepsia com clorexidina a $0,12 \%$ (Periogard - Colgate - Palmolive Indústria Ltda.) foi realizada a abertura coronária pela face oclusal utilizando pontas esféricas diamantadas nº 1015 (K.G. Sorensen - São Paulo - SP - Brasil) 
montadas em motor de alta rotação, refrigeradas com ar/água, complementadas com pontas diamantadas cônicas de extremidade inativa ( $n^{\circ} 3083$ - KG Sorensen).

Após a abertura da câmara pulpar, a polpa foi removida com uma lima tipo Hedströem e os canais radiculares foram mantidos abertos por 7 dias para que houvesse uma contaminação natural pelos micro-organismos bucais. Após o período de 7 dias, os dentes foram selados provisoriamente com mechas de algodão e cimento de óxido de zinco e eugenol (IRM ${ }^{\circledR}$ - Dentsply Indústria e Comércio Ltda. - Petrópolis - Brasil), para que pudesse ser formado um ambiente de anaerobiose, após a contaminação bacteriana, e consequentemente, a formação de lesão periapical (Leonardo et al., 1993).

Após a indução das lesões periapicais, que foram evidenciadas radiograficamente após 45 a 60 dias, iniciou-se o tratamento endodôntico sob isolamento absoluto com dique de borracha, e antissepsia com digluconato de clorexidina a 2,0\% (FCFRP - USP - Ribeirão Preto - SP). O cimento provisório e a mecha de algodão da câmara pulpar foram removidos com pontas diamantadas esféricas e os canais radiculares submetidos à neutralização imediata do conteúdo séptico-tóxico aplicando o princípio coroa/ápice (Leonardo, 2005), Foram empregados instrumentos de níquel-titânio do Sistema Protaper Universal (Dentsply/Maillefer), introduzindo os instrumentos com diminuição gradativa de diâmetros, acompanhados pela irrigação/aspiração e nova inundação com solução de hipoclorito de sódio a 2,5\% (FCFRP, USP - Ribeirão Preto, SP).

Realizada a odontometria, pelo método radiográfico, e determinado 0 Comprimento Real de Trabalho (CRT), foi realizado o arrombamento do forame apical empregando limas tipo $K$ de $n^{\circ} 15,20$ e 25, sendo esta última lima designada de Instrumento Apical Foraminal (IAF), utilizada para padronização do diâmetro de abertura apical dos dentes em estudo. Na mesma sessão, foi realizado o preparo biomecânico dos canais radiculares, empregando instrumentos de níquel-titânio do Sistema Protaper Universal (Dentsply/Maillefer) até a lima F5, no CRT, estabelecido aproximadamente a $1 \mathrm{~mm}$ aquém do ápice radiográfico. Após a utilização de cada instrumento, foi realizada a 
irrigação/aspiração/inundação dos canais radiculares com $2 \mathrm{~mL}$ de solução de hipoclorito de sódio a 2,5\%.

Terminado o preparo biomecânico, o IAF foi novamente inserido em todo o comprimento do dente, para remoção de possíveis raspas de dentina e resíduos acumulados na região do forame apical, em decorrência do preparo biomecânico. Após nova irrigação e aspiração, os canais radiculares foram secos com pontas de papel absorvente esterilizadas e, a seguir, inundados com solução de ácido etilenodiaminotetracético (EDTA), tamponado em pH 7,4 até o CRT e agitado por 3 minutos com a lima. Após irrigação copiosa com solução de hipoclorito de sódio a $1 \%$ para neutralização do EDTA, foi realizada nova secagem por aspiração e uso de pontas de papel absorvente, de calibre compatível com o diâmetro do último instrumento utilizado no CRT. A seguir, os procedimentos foram realizados de acordo com a técnica estabelecida para cada grupo.

No grupo experimental, após o preparo biomecânico, a pasta à base de hidróxido de cálcio (Calen ${ }^{\circledR}$ ) foi aplicada apenas na medida de $1 \mathrm{~mm}$ além do CRT, com a finalidade de promover um leve extravasamento e proporcionar seu contato com a superfície apical externa, sem preencher o canal radicular. Este procedimento foi realizado com o auxílio de seringa rosqueável ML (S.S. White Artigos Dentários Ltda. - Rio de Janeiro - Brasil) e agulha longa 27G (Septoject $\mathrm{XL}$ - Septodont - França) sendo realizadas tomadas radiográficas para a comprovação do extravasamento. A seguir, a limpeza e secagem dos canais radiculares foi realizada com pontas de papel absorventes esterilizadas e os mesmos foram obturados com o cimento AH Plus (Dentsply/Detrey - Kontstanz - Alemanha) e cones de guta-percha, usando a técnica de condensação lateral. Após o corte do excesso da obturação, as câmaras pulpares foram limpas com mechas de algodão esterilizadas umedecidas em álcool, sendo os dentes restaurados com amálgama de prata (Velvalloy - S.S.White Art. Dent. Ltda. - Rio de Janeiro - Brasil), condensado sobre uma base de cimento de ionômero de vidro (Vidrion F - S.S.White Art. Dent. Ltda.).

No grupo controle positivo, os canais foram preenchidos com pasta à base de hidróxido de cálcio (Calen ${ }^{\circledR}$ ), empregada com o auxílio da seringa endodôntica rosqueável ML ${ }^{\circledR}$ (Duflex - S.S. White Artigos Dentários Ltda.) e agulha longa 27G 
(Septoject XL - Septodont), com tope de borracha, na medida do CRT. Com a finalidade de proporcionar seu contato com a superfície apical externa, um pequeno extravasamento da pasta foi realizado posicionando a agulha na longitude do CRT, sendo realizadas tomadas radiográficas para a comprovação do preenchimento total dos canais radiculares e do extravasamento. Após a colocação de uma mecha de algodão esterilizada na entrada dos canais radiculares, foi realizado o selamento coronário com cimento à base de ionômero de vidro (Vidrion R - S.S.White Art. Dent. Ltda.), durante 14 dias. Decorrido este período, após novo isolamento absoluto o selamento coronário foi removido com pontas diamantadas e o curativo foi removido por meio de irrigações sucessivas com solução salina esterilizada, sendo então novamente empregada a solução de EDTA por 3 minutos, seguida do uso de solução salina esterilizada e secagem dos canais com pontas de papel absorvente. A seguir, os canais foram obturados e restaurados da mesma maneira descrita no grupo experimental.

No grupo controle negativo, após a realização do preparo biomecânico, os canais radiculares foram obturados na mesma sessão e restaurados como descrito nos grupos anteriores. Todos os dentes tratados em todos os grupos foram radiografados antes e após 120 dias do tratamento endodôntico.

Decorrido o período experimental de 120 dias, após o exame radiográfico periapical de acompanhamento, os animais foram submetidos à eutanásia por sobredose anestésica, de acordo com as Diretrizes da prática de Eutanásia do CONCEA do Ministério da Ciência e Tecnologia. Inicialmente, foi realizada a anestesia por meio de injeção por via endovenosa de acepromazina (Acepran $0,2 \%$ ), na dosagem de $0,2 \mathrm{mg} / \mathrm{kg}$ de peso. Após 15 minutos, foi realizada a anestesia com Tiopental (Thionembutal - Abbot Laboratórios do Brasil Ltda. - Rio de Janeiro - RJ - Brasil) endovenoso, na dosagem de $25 \mathrm{mg} / \mathrm{kg}$ de peso. Em seguida, foi realizada a eutanásia com cloreto de potássio a $20 \%$, via endovenosa, na dosagem de $100 \mathrm{mg} / \mathrm{kg}$ de peso, injetado lentamente.

\subsection{Análise radiográfica}

As imagens radiográficas, obtidas antes e 120 dias após o tratamento endodôntico foram fotografadas, digitalizadas e transferidas para o programa 
Image J 1.28 u (National Institutes of Health - Califórnia - EUA) para mensuração das áreas radiolúcidas periapicais. A delimitação e a medida da área radiolúcida sugestiva de lesão periapical presente em cada raiz foi determinada em $\mathrm{mm}^{2}$.

Foram incluídas áreas radiolúcidas sugestivas de lesões periapicais sendo excluídos osso alveolar e estruturas dentais radiopacas como representada na Figura 1 . O percentual de redução da área radiolúcida foi obtido para cada raiz.

Figura 1. Imagem representativa da radiografia prévia ao tratamento endodôntico ( 0 dias) ilustrando a técnica utilizada na mensuração da área radiolúcida periapical (linha amarela)

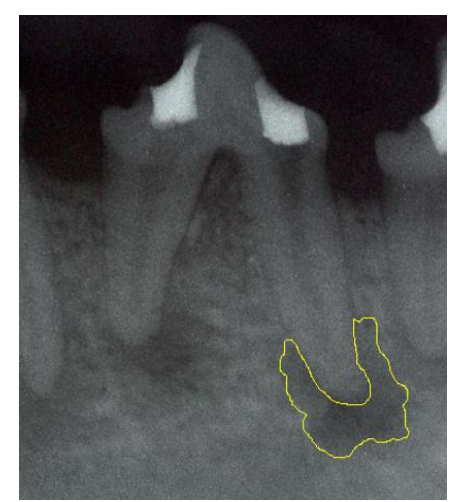

\subsection{Processamento histotécnico e análise histopatológica.}

Após a eutanásia dos animais, as maxilas e mandíbulas foram dissecadas, com auxílio de um bisturi, reduzidas em seu volume e lavadas em água corrente. Para facilitar o processamento histotécnico, as peças foram seccionadas utilizando discos diamantados, sob constante refrigeração com água obtendo-se blocos das peças anatômicas contendo os dentes individualmente.

As peças foram submetidas à fixação em solução de formol tamponado a $10 \%$, por 48 horas, à temperatura ambiente. Posteriormente, as peças foram imersas em um recipiente de vidro contendo uma solução à base de ácido etilenodiaminotetracético (EDTA Disodium Salt Dihydrate - Merck - Darmstadt Alemanha) a $10 \%$ e submetidas à desmineralização acelerada pelo Vortex tipo Agitador KLINE NT151 (Novatecnica ${ }^{\circledR}$ - Piracicaba - São Paulo - Brasil). As peças foram imersas em solução desmineralizadora de EDTA a 22\% e colocadas em agitação orbital a 70\%, 8 horas por dia. No intervalo entre os dias, as peças permaneceram na solução de EDTA sem agitação, na temperatura ambiente. A solução desmineralizadora foi trocada semanalmente. A completa descalcificação 
das amostras, avaliada por meio da penetração de uma agulha para verificação da sua consistência, foi obtida aproximadamente em 30 dias (Flower, 1951).

Concluída a desmineralização, as peças foram neutralizadas em solução de sulfato de sódio a 5\% (Sulfato de Sódio Anhidro - J.T.Baker - Fisher Sci. USA) por 24 horas, lavadas em água corrente por 8 horas, desidratadas em concentrações crescentes de álcool (Álcohol Etílico Absoluto Anhidro ${ }^{\circledR}$-J.T.Baker - Fisher Sci. - USA), imersas em álcool xilol 50\% por 30 min, diafanizadas em xilol $100 \%$ (Xylol ${ }^{\circledR}$ - Merck - Alemanha), trocado a cada hora por 3 vezes, e inclusas em parafina (Histosec ${ }^{\circledR}$ Pastillen - Merck - Alemanha), de acordo com a rotina histotécnica. Os blocos contendo as raízes individualizadas foram reduzidos pela microtomia a cortes seriados longitudinais com $5 \mu \mathrm{m}$ de espessura em sentido mesio-distal.

Os cortes foram corados com hematoxilina e eosina (HE). Para a avaliação histopatológica, as lâminas foram observadas no microscópio AXIO IMAGER.M1 (Zeiss, Gottingen - Alemanha) operando em modo convencional e modo fluorescência (Leica DMR - Leica Microsystem Wetzlar Gmbh - Wetzlar Alemanha). As avaliações quantitativas foram realizadas por meio do software AXIOVISION rel 4.8 (Zeiss, Gottingen). Para a análise histopatológica, os espécimes foram classificados de acordo cos seguintes parâmetros: infiltrado inflamatório (ausente, suave, moderado ou severo), espessura do ligamento periodontal (normal - 0 a 0,3 mm, levemente aumentado - 0,31 a 0,50 mm, moderadamente aumentado - 0,51 a 0,80 $\mathrm{mm}$ ou severamente aumentado acima de $0,81 \mathrm{~mm}$ ), selamento apical (completo, parcial ou ausente), reabsorção cementária (ausente ou presente) e reabsorção óssea (ausente ou presente). Os valores de referência para classificação da espessura do ligamento periodontal foram obtidos a partir de medidas realizadas em dentes de cães hígidos ou portadores de lesões periapicais não tratados (lâminas de arquivo do DCI-FORPUSP). A média da espessura do ligamento periodontal de cada raiz foi calculada com base em medidas lineares $(\mathrm{mm})$ partindo da superfície do cemento em direção à superfície do osso alveolar, realizadas em 4 regiões equidistantes, tendo o forame apical como referência. 


\subsection{Forma de análise dos resultados}

Os resultados foram analisados utilizando o programa estatístico Graph Pad Prism 4 (Graph Pad Software Inc, San Diego, CA, EUA). Os resultados foram analisados inicialmente com os testes de Kolmogorov-Smirnov e Shapiro Wilk para avaliar o tipo de distribuição das amostras obtidas. Os valores finais obtidos na avaliação radiográfica e da espessura do ligamento periodontal foram analisados por meio da análise de variância (ANOVA) e pós teste de Tukey, com nível de significância de 5\%. Os parâmetros histopatológicos foram analisados utilizando o teste chi-quadrado $\left(x^{2}\right)$ e em resultados dicotômicos, o teste exato de Fisher, com nível de significância de 5\%. 

4. Resultados

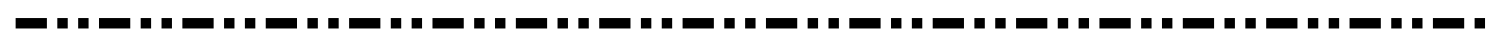





\subsection{Análise radiográfica}

De acordo com os resultados radiográficos, aos 120 dias após tratamento, o percentual médio de redução da área radiolúcida ( \pm erro padrão da média) no grupo com novo protocolo foi de $62,55 \%( \pm 3,709)$. No grupo controle positivo, verificou-se redução de $66,83 \%( \pm 6,627)$ na área radiolúcida periapical e no grupo controle negativo observou-se uma redução de $33,53 \%( \pm 8,607)$ na área radiolúcida periapical. Os percentuais médios de redução da área de cada grupo encontram-se na Figura 2.

$\mathrm{Na}$ análise estatística verificou-se que as porcentagens de redução da área radiolúcida foram semelhantes no grupo experimental e no grupo controle positivo ( $p>0,05)$, e que ambos resultaram numa redução superior ao controle negativo, onde não foi utilizado o curativo de demora com pasta à base de hidróxido de cálcio $(p<0,01)$.

Figura 2. Percentual de redução na imagem radiolúcida periapical após a realização dos tratamentos endodônticos nos grupos experimental (Novo protocolo) e controles positivo (Duas sessões com aplicação de curativo de demora com pasta à base de $\mathrm{CaOH}_{2}$ ) e negativo (Sessão única sem curativo de demora) ns= diferença não significante

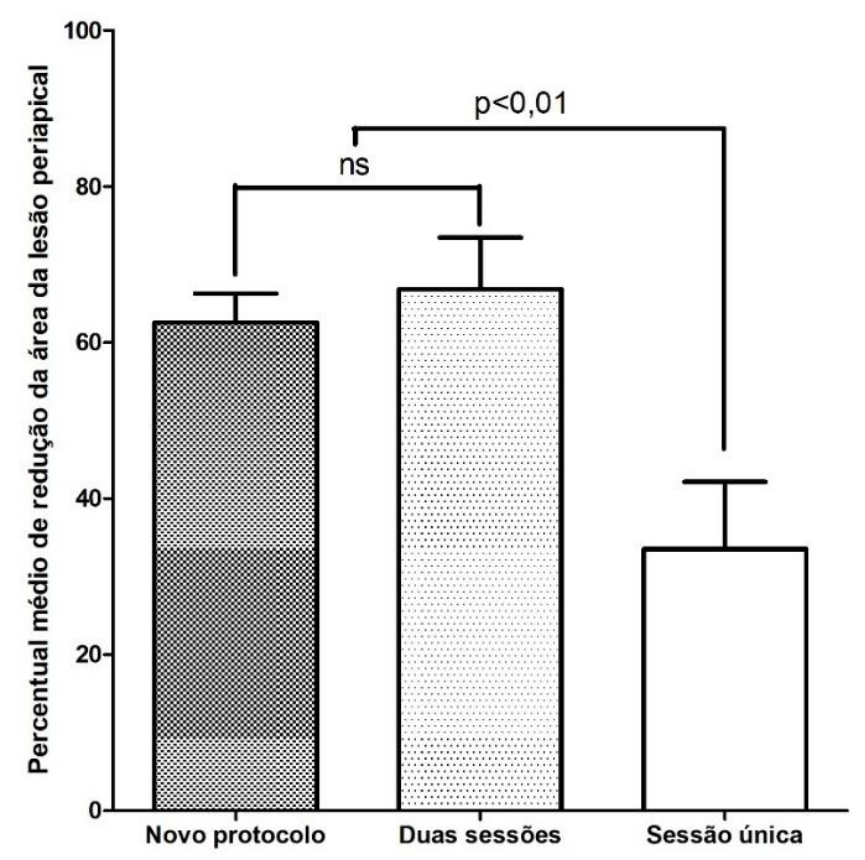




\subsection{Análise histopatológica}

De um total de 60 raízes inicialmente tratadas, 13 raízes foram perdidas durante o processamento histotécnico. Restaram 22 raízes para o novo protocolo de tratamento, 13 raízes para o tratamento em duas sessões e 12 raízes para o tratamento em sessão única.

No grupo experimental, 120 dias após o tratamento endodôntico com ligeiro extravasamento de pasta à base de hidróxido de cálcio na região periapical e obturação na mesma sessão, foi observada presença de processo de reparo em evolução. A espessura do ligamento periodontal apresentava-se levemente aumentada em 4 casos $(18,18 \%)$, moderadamente aumentada em 13 raízes $(59,09 \%)$ e severamente aumentada em 5 raízes (22,72\%) (Tabelas 2 e 3). No espaço do ligamento periodontal foi observada presença de células inflamatórias, de padrão mononuclear, em intensidade suave em 17 casos $(77,3 \%)$ e moderada em 5 casos (22,7\%) (Tabela 2).

Com relação ao selamento apical, verificou-se selamento total em 4 $(18,2 \%)$ das 22 raízes, sendo que $8(36,4 \%)$ apresentaram selamento parcial e 10 (45,4\%) evidenciaram ausência de selamento (Tabela 2 e Figura 4). Na região do ápice, as lacunas cementárias apresentavam-se vazias na maioria dos espécimes e a superfície externa do cemento radicular apresentava áreas de reabsorção reparadas, com deposição de tecido mineralizado (95,5\%), e não reparadas (inativas, 4,5\%), com reinserção de fibras colágenas (Figura 4G e H). A superfície óssea apresentou-se regular e com ausência de reabsorção em 100\% dos casos. Ainda, observou-se, na maioria dos casos, que mesmo quando esse tratamento permitiu a formação de tecido mineralizado, houve presença suave de fibras colágenas paralelas e poucos vasos sanguíneos (Figura 4G).

$\mathrm{Na}$ avaliação em microscopia de fluorescência foi possível observar com maior detalhe a reinserção de fibras colágenas na superfície do cemento e o padrão morfológico do tecido mineralizado neoformado. As novas redes de colágeno, presentes no espaço de ligamento periodontal, eram compatíveis com um ligamento desorganizado, em fase de reparação após processo inflamatório (Figura $5 \mathrm{G} \mathrm{e} \mathrm{H}$ ). Observou-se que o selamento apical biológico se iniciava com a deposição das fibras colágenas partindo da periferia, nas paredes do canal 
cementário, para o centro do forame apical (Figura 5 A e B). As lacunas de reabsorção na superfície cementária foram reparadas com cemento do tipo celular, sendo depositado a partir de sua superfície externa, atingindo o interior das lacunas (Figura 5 C-E).

No grupo submetido ao tratamento em duas sessões com utilização de curativo de demora pasta à base de hidróxido de cálcio, foi observado reparo em estágio mais avançado. O ligamento periodontal encontrava-se levemente aumentado em 3 das 13 raízes $(23,1 \%)$, moderadamente aumentado em 8 $(61,53 \%)$ e severamente aumentado em 2 raízes $(15,4 \%)$. O infiltrado inflamatório apresentou-se suave em 11 raízes $(84,6 \%)$ e moderado em 2 $(15,4 \%)$, com natureza mononuclear. Evidenciou-se processo de selamento apical com deposição de cemento celular em estágio completo em 4 casos $(30,8 \%)$, parcial em $7(53,84 \%)$ e 2 casos $(15,4 \%)$ não evidenciaram selamento (Tabela 2). O cemento radicular apresentava áreas de reabsorção inativas, em 100\% dos espécimes, sendo observada reinserção das fibras de Sharpey no cemento celular neoformado e osso alveolar em reparação. A superfície óssea apresentou-se regular e com ausência de reabsorção em $100 \%$ dos casos. 0 ligamento periodontal evidenciava estágio evoluído de reparado, com fibras colágenas e vasos sanguíneos neoformados (Figura 6).

A avaliação com microscopia de fluorescência, evidenciou deposição de fibras colágenas mais organizadas na região periapical (Figura $6 \mathrm{H}$ ). No cemento apical, as linhas de reversão encontravam-se separando o cemento residual após processo inflamatório e cemento celular neoformado reparando as áreas de reabsorção. Também foi observada presença de fibras colágenas no espaço do ligamento periodontal, reinseridas na superfície do cemento e osso alveolar.

No grupo tratado em sessão única foi observada persistência das lesões periapicais após 120 dias de realização do tratamento endodôntico e ausência de reparo. O ligamento periodontal apresentava-se moderadamente aumentado em 2 casos $(16,6 \%)$ e severamente aumentado em 10 (83,4\%). Neste espaço observou-se presença de infiltrado inflamatório suave em 2 raízes (16,7\%), moderado em 4 (33,33\%) e severo em 6 (50\%), de natureza mista, com células mononucleares e algumas polimorfonucleares. Neste grupo, havia ausência de 
selamento apical em $100 \%$ dos casos (12 raízes). Verificou-se persistência de áreas de reabsorção na superfície externa e interna do cemento e osso alveolar (100\%), com ausência de fibras colágenas e neoformação de vasos sanguíneos, caracterizando um tecido ainda inflamado (Figura 7).

Tabela 2. Distribuição de número de raízes (percentual) encontradas em cada escore de cada parâmetro, de acordo com a análise histopatológica e estatística realizada nos espécimes após 120 dos tratamentos endodônticos

\begin{tabular}{|c|c|c|c|c|}
\hline \multirow[b]{2}{*}{$\begin{array}{c}\text { Parâmetro } \\
\text { histopatológico }\end{array}$} & \multirow[b]{2}{*}{ Escores } & \multicolumn{3}{|c|}{ Protocolo de Tratamento } \\
\hline & & $\begin{array}{c}\text { Novo } \\
\text { Protocolo } \\
\text { n (\%) }\end{array}$ & $\begin{array}{c}\text { Tratamento em } \\
\text { duas sessões } \\
\text { n (\%) }\end{array}$ & $\begin{array}{c}\text { Tratamento em } \\
\text { sessão única } \\
\text { n (\%) }\end{array}$ \\
\hline \multirow{5}{*}{$\begin{array}{c}\text { Infiltrado } \\
\text { Inflamatório }\end{array}$} & Ausente & $0(0,0)$ & $0(0,0)$ & $0(0,0)$ \\
\hline & Suave & $17(77,3)$ & $11(84,6)$ & $2(16,7)$ \\
\hline & Moderado & $5(22,7)$ & $2(15,4)$ & $4(33,3)$ \\
\hline & Severo & $0(0,0)$ & $0(0,0)$ & $6(50,0)$ \\
\hline & Análise estatística & a & a & b \\
\hline \multirow{5}{*}{$\begin{array}{l}\text { Espessura do } \\
\text { ligamento } \\
\text { periodontal }\end{array}$} & Normal & $0(0,0)$ & $0(0,0)$ & $0(0,0)$ \\
\hline & $\begin{array}{l}\text { Levemente } \\
\text { aumentado }\end{array}$ & $4(18,18)$ & $3(23,1)$ & $0(0,0)$ \\
\hline & $\begin{array}{l}\text { Moderadamente } \\
\text { aumentado }\end{array}$ & $13(59,09)$ & $8(61,53)$ & $2(16,6)$ \\
\hline & $\begin{array}{l}\text { Severamente } \\
\text { aumentado }\end{array}$ & $5(22,72)$ & $2(15,4)$ & $10(83,4)$ \\
\hline & Análise estatística & a & a & b \\
\hline \multirow{3}{*}{$\begin{array}{l}\text { Reabsorção } \\
\text { cementária }\end{array}$} & Ausente & $21(95,5)$ & $13(100,0)$ & $0(0,0)$ \\
\hline & Presente & $1(4,5)$ & $0(0,0)$ & $12(100,0)$ \\
\hline & Análise estatística & a & $\mathbf{a}$ & b \\
\hline \multirow{4}{*}{$\begin{array}{l}\text { Selamento } \\
\text { apical }\end{array}$} & Completo & $4(18,2)$ & $4(30,8)$ & $0(0,0)$ \\
\hline & Parcial & $8(36,4)$ & $7(53,84)$ & $0(0,0)$ \\
\hline & Ausente & $10(45,4)$ & $2(15,4)$ & $12(100,0)$ \\
\hline & Análise estatística & a & a & b \\
\hline \multirow{3}{*}{$\begin{array}{c}\text { Reabsorção } \\
\text { óssea }\end{array}$} & Ausente & $22(100,0)$ & $13(100,0)$ & $1(8,3)$ \\
\hline & Presente & $0(0,0)$ & $0(0,0)$ & $11(91,7)$ \\
\hline & Análise estatística & a & $\mathbf{a}$ & b \\
\hline
\end{tabular}


Figura 3. Percentual de casos de cada grupo apresentando os escores mais significativos de cada parâmetro analisado, 120 dias após tratamento endodôntico correspondente $* *$ : diferença estatística significante $(p<0,01)$ ns: diferença estatística não significante
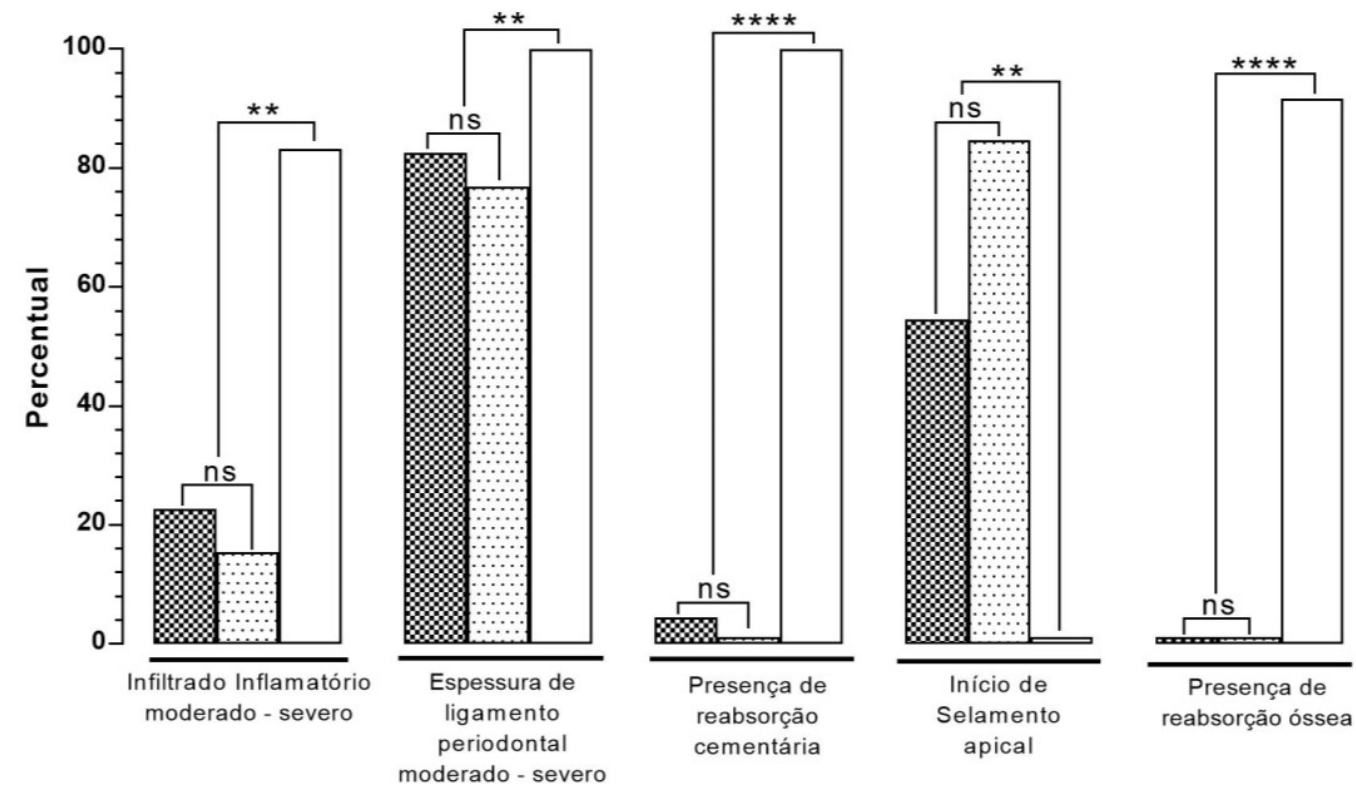

Novo protocolo

$\because$ Duas sessões Sessão única

Tabela 3. Valores obtidos na análise dos resultados da mensuração da espessura do ligamento periodontal 120 dias após tratamento endodôntico

\begin{tabular}{|c|c|c|c|}
\hline $\begin{array}{l}\text { Protocolo do } \\
\text { tratamento }\end{array}$ & & $\begin{array}{c}\text { Espessura do } \\
\text { ligamento periodontal } \\
(\mathrm{mm})\end{array}$ & P valor* \\
\hline Novo protocolo & $\begin{array}{c}\text { Media } \\
\text { Desv. Pad. } \\
\text { Mediana }\end{array}$ & $\begin{array}{c}(0,32) a \\
(0,28) \\
(0,29)\end{array}$ & \\
\hline $\begin{array}{l}\text { Tratamento em } \\
\text { duas sessões }\end{array}$ & $\begin{array}{c}\text { Media } \\
\text { Desv. Pad. } \\
\text { Mediana }\end{array}$ & $\begin{array}{c}(0,31) a \\
(0,21) \\
(0,19)\end{array}$ & $<0,0001$ \\
\hline $\begin{array}{l}\text { Tratamento em } \\
\text { sessão única }\end{array}$ & $\begin{array}{l}\text { Media } \\
\text { Desv. Pad. } \\
\text { Mediana }\end{array}$ & $\begin{array}{c}(1,26) b \\
(0,45) \\
(1,29)\end{array}$ & \\
\hline
\end{tabular}

* De acordo com os resultados da análise de variância e pós-teste de Dunn para múltiplas comparações. Letras distintas indicam diferença estatística. 
Figura 4. Fotomicrografias representativas 120 dias após tratamento endodôntico com o novo protocolo com extravasamento de pasta à base de hidróxido de cálcio e obturação na mesma sessão, evidenciando os eventos microscópicos observados na análise descritiva das regiões apical e periapical, em microscopia de luz convencional (A, C, E e G) e de fluorescência (B, D, F e H):

(A e B) Fotomicrografia panorâmica da região apical e periapical evidenciando espaço do ligamento periodontal suavemente aumentado, cemento apical o e osso alveolar com superfície regular e selamento parcial do forame apical (Zeiss, 5X);

(C e D) Fotomicrografia panorâmica da região apical e periapical evidenciando espaço do ligamento periodontal (LP) levemente aumentado e osso alveolar com superfície regular e reparado e selamento completo do forame apical (Zeiss, 5X);

(E e F) Fotomicrografia panorâmica da região apical e periapical evidenciando deposição de cemento nas paredes do forame apical, espaço do ligamento periodontal reparado, e osso alveolar com superfície regular, presença de osteócitos em lacunas internas e presença de selamento parcial do forame apical (Zeiss, 20X);

(G e H) Fotomicrografia da região periapical evidenciando deposição de cemento nas lacunas de Howship inativas e reinserção de fibras colágenas (Zeiss, 40X). 

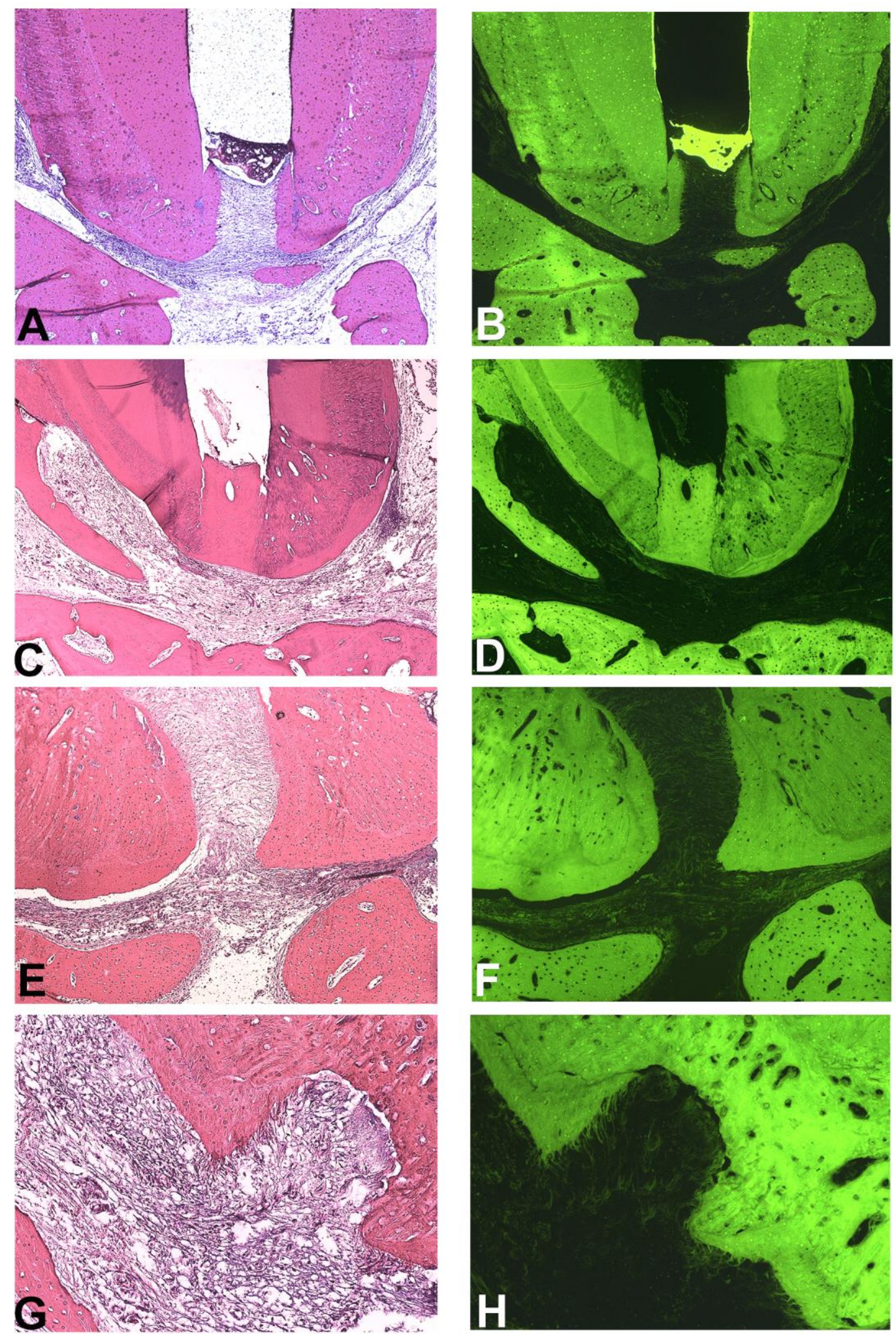
Figura 5. Fotomicrografia representativas dos estágios de selamento apical e reparação cementária observados na análise descritiva das regiões apical e periapical, em microscopia de fluorescência: 120 dias após tratamento endodôntico com o novo protocolo com extravasamento de pasta à base de hidróxido de cálcio e obturação na mesma sessão, evidenciando:

(A) Fotomicrografia panorâmica da região apical e periapical evidenciando espaço do ligamento periodontal levemente aumentado, cemento apical e osso alveolar com superfícies regulares e selamento parcial do forame apical (Zeiss, 10X);

(B) Fotomicrografia região apical e periapical evidenciando inserção de fibras colágenas no cemento depositado nas paredes do forame apical e preenchimento das lacunas aumentadas de cementócitos com cemento celular (Zeiss, 20X);

(C) Fotomicrografia da região apical evidenciando preenchimento das lacunas de cementócitos aumentadas (Alexa Flúor, Zeiss, 40X);

(D) Fotomicrografia da região apical e periapical evidenciando formação da linha de reversão entre cemento remanescente e cemento celular neoformado (Zeiss, 40X);

(E) Fotomicrografia da região apical e periapical evidenciando deposição de cemento celular, invaginações em lacunas de Howship inativas e lacunas de cementócitos, espaço do ligamento periodontal reparado e superfície do osso alveolar regular (Zeiss, 20X);

(F) Fotomicrografia panorâmica da região apical e periapical evidenciando espaço do ligamento periodontal reparado, cemento celular e osso alveolar com superfícies regulares e reparado e selamento completo do forame apical com regiões em processo de mineralização (Zeiss, 10X). 

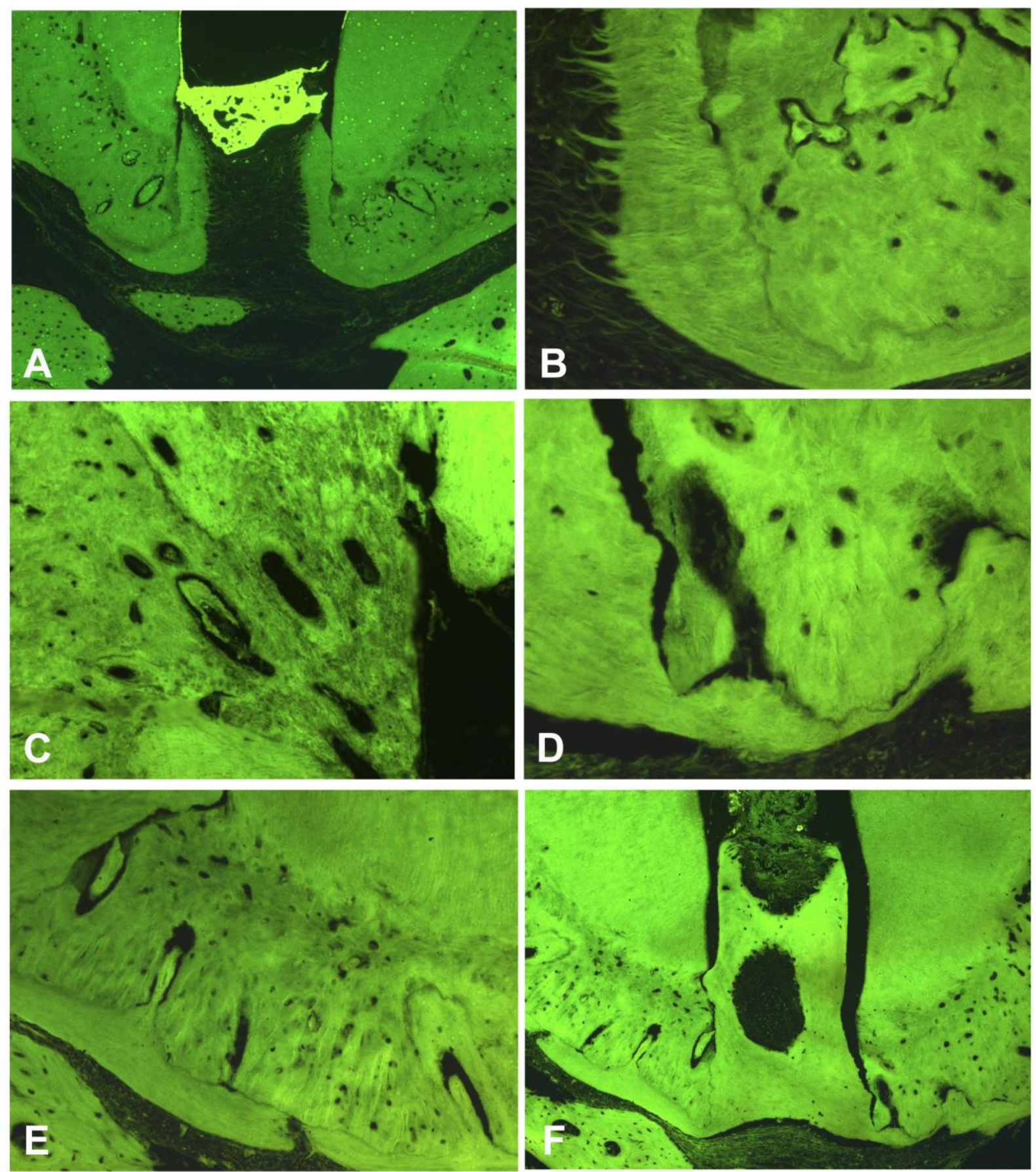
Figura 6. Fotomicrografias representativas 120 dias após tratamento endodôntico em duas sessões com utilização de curativo de demora à base de hidróxido de cálcio, evidenciando os eventos microscópicos observados na análise descritiva das regiões apical e periapical, em microscopia de luz convencional ( $A, C$, E e G) e de fluorescência (B, D, F e H):

(A e B) Fotomicrografia panorâmica da região apical e periapical evidenciando espaço do ligamento periodontal reparado, cemento apical e osso alveolar com superfícies regulares e reparado e selamento completo do forame apical (Zeiss, 5X);

(C e D) Fotomicrografia panorâmica da região apical e periapical evidenciando deposição de cemento nas paredes do forame apical e deposição de fibras colágenas no espaço do forame apical. (Zeiss, 20X);

(E e F) Fotomicrografia da região periapical evidenciando deposição de cemento nas lacunas de Howship inativas e reinserção de fibras colágenas (Zeiss, 40X);

(G) Fotomicrografia da região periapical evidenciando tecido de reparação (Zeiss, 40x);

(H) Fotomicrografía da região do ligamento periodontal evidenciando abundante deposição de fibras colágenas. (Zeiss, 40x). 

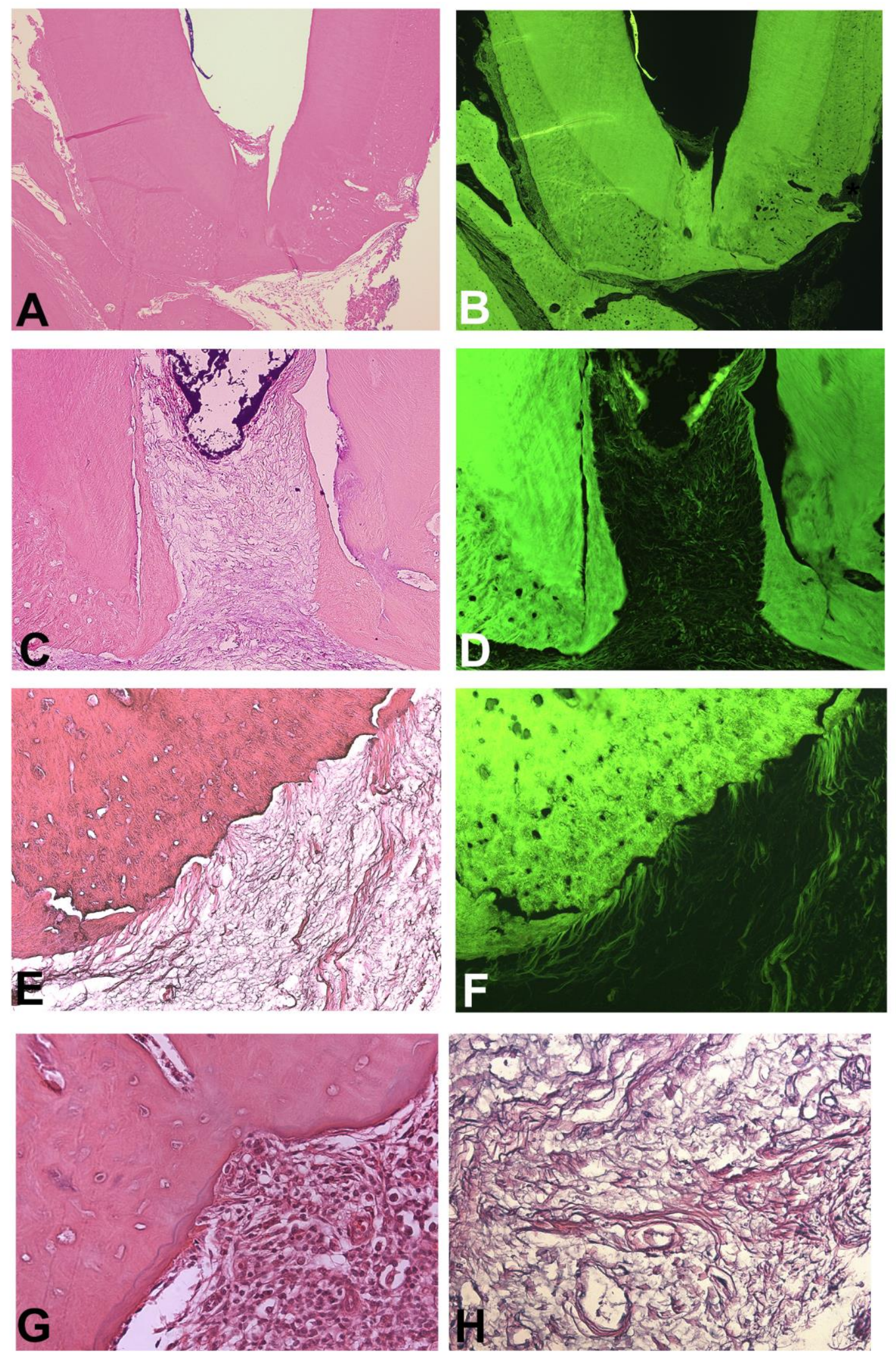
Figura 7. Fotomicrografias representativas 120 dias após tratamento endodôntico em sessão única, evidenciando os eventos microscópicos observados na análise descritiva das regiões apical e periapical, em microscopia de luz convencional $(A$, $C, E$ e G) e de fluorescência (B, D, F e H):

(A e B) Fotomicrografia panorâmica da região apical e periapical evidenciando espaço do ligamento periodontal severamente aumentado, cemento e osso alveolar com superfície irregular e lacunas de Howship ativas e ausência de selamento parcial do forame apical (Zeiss, 5X);

(C e D) Fotomicrografia panorâmica da região apical e periapical evidenciando espaço do ligamento periodontal severamente aumentado, cemento dental e osso alveolar severamente reabsorvidos e selamento do forame apical (E e F) ausente (Zeiss, 5X);

Fotomicrografia da região apical e periapical evidenciando ausência de deposição de cemento nas paredes do forame apical, infiltrado inflamatório severo e reabsorção interna e

(G e H) externa do cemento dental remanescente (Zeiss, 20X);

Fotomicrografia da região apical evidenciando reabsorção severa do cemento radicular e ausência de deposição de fibras colágenas (Zeiss, 40X). 

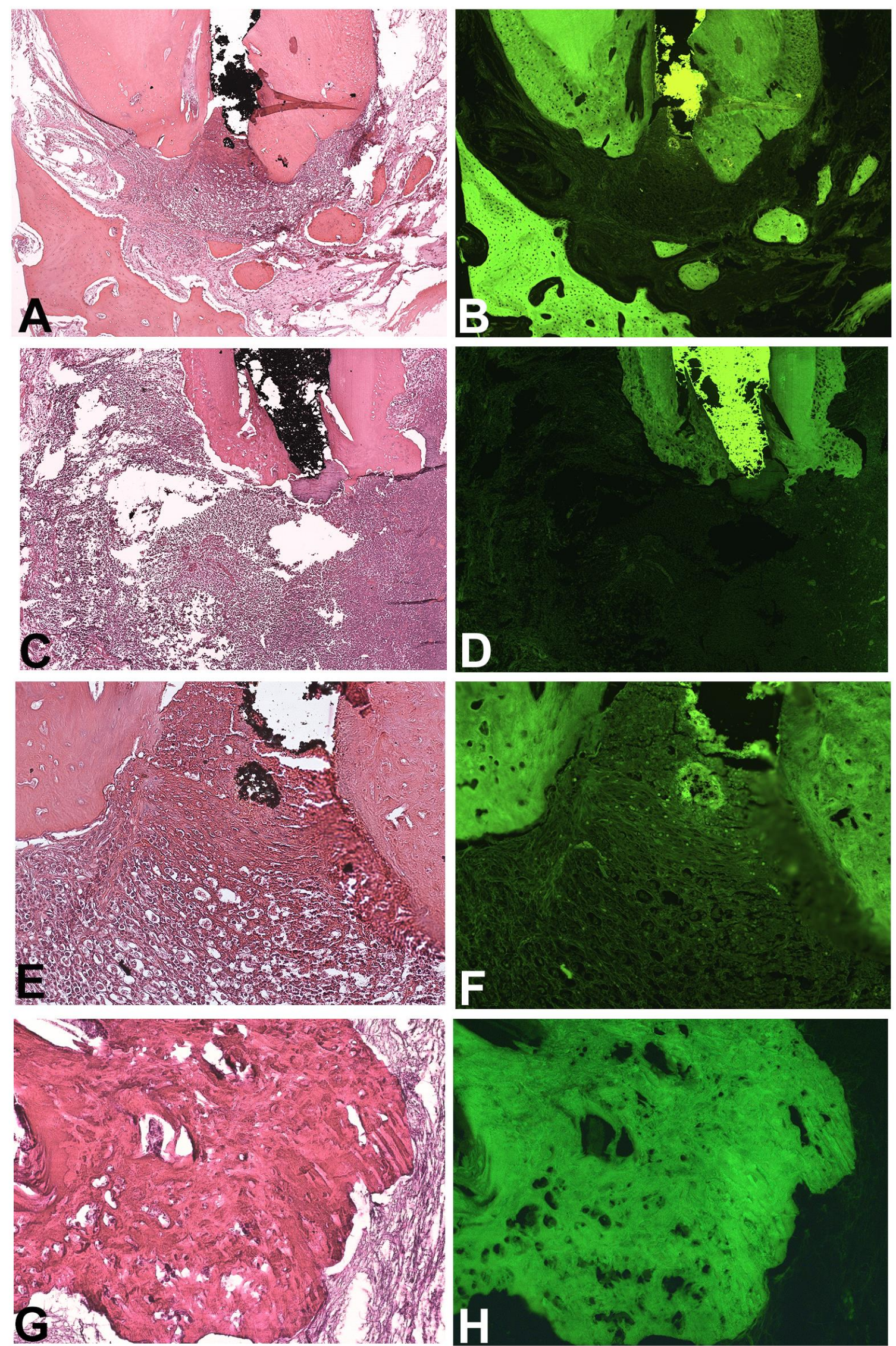

5. Discussão

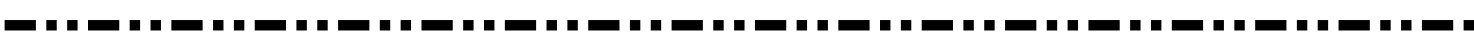



O presente trabalho teve como objetivo avaliar a eficácia de um novo protocolo de tratamento endodôntico realizado por meio de um pequeno extravasamento de pasta à base de hidróxido de cálcio seguido de obturação do canal na mesma sessão. Este protocolo foi avaliado na resposta tecidual de dentes de cães, com rizogênese completa, portadores com lesão periapical induzida experimentalmente. Sabe-se que a aplicação de curativo de demora com hidróxido de cálcio apresenta propriedades fundamentais, para o reparo da periodontite apical elevando o seu sucesso clínico, radiográfico, histológico e microbiológico (Sjögren et al., 1991; Leonardo et al., 1995; Capik et al., 2005; Leonardo et al., 2006; Estrela et al., 2008; Hidalgo et al., 2016; Queiroz et al., 2016). No entanto, o tempo clínico e custo do tratamento decorrentes deste protocolo de tratamento, que exige duas sessões, são maiores. Assim, o desenvolvimento de um novo protocolo de tratamento que permitisse associar as vantagens biológicas da utilização do curativo de demora à vantagem clínica da obturação em sessão única apresentaria grande benefício.

O novo protocolo proposto, obtido por meio do extravasamento de pasta à base de hidróxido de cálcio seguida pela obturação de dentes na mesma sessão não havia sido anteriormente proposto na literatura. Em estudos anteriores a aplicação do pó de hidróxido de cálcio previamente à obturação foi proposta com finalidade diferente do presente estudo, a de promover a formação de um "plug apical" em dentes com canais amplos ou sobre-instrumentados (Holland, Souza, Nery et al., 1979; Holland et al., 1980; Pitts et al., 1984). Nesta técnica, o material é aplicado na região cervical do canal radicular, com auxílio de um amalgamador, sendo a seguir empurrado ao ápice com limas com o objetivo de formar uma barreira física visando evitar o extravasamento do material obturador. Nestes casos, também observa-se ocorrência de reparação tecidual e início da formação de barreira de tecido mineralizado na região apical após 3 meses do contato direto com o hidróxido de cálcio (Holland et al., 1979; Holland et al., 1980; Pitts et al., 1984; Holland et al., 1984). O hidróxido de cálcio é considerado o material de escolha para a medicação entre sessões em dentes com periodontite apical por apresentar propriedades antibacterianas, inativar a endotoxina bacteriana (Bystrom et al., 1985; Haasapalo e Orstavik, 1987; Nelson-Filho et al., 2002; 
Leonardo et al., 2006), ser biocompatível (Nelson-Filho et al., 1999; Leonardo et al., 2006), ativar a enzima fosfatase alcalina promovendo mineralização (Leonardo et al., 2006; Silva et al., 2008) entre outras; e seu ligeiro extravasamento para regiões periapicais, obtido no presente estudo com auxílio de agulha e seringa endodôntica via canal radicular, poderia auxiliar no combate à infecção extrarradicular, atingindo o biofilme bacteriano persistente, que constitui o principal fator de insucesso nos tratamentos endodônticos.

No presente estudo, na avaliação radiográfica, o novo protocolo de tratamento resultou em uma porcentagem de redução das áreas radiolúcidas sugestivas de lesão periapical semelhante ao tratamento convencional em duas sessões. No entanto, na análise histopatológica, embora o espaço do ligamento periodontal tenha sido semelhante, o novo protocolo apresentou processo de reparação em estágio inicial, menos avançado quando comparado ao protocolo convencional de tratamento em duas sessões. Esta diferença de resultados radiográficos e histopatológicos de devem ao fato de que as áreas radiolúcidas observadas radiograficamente nos grupos com novo protocolo de tratamento e em duas sessões representam tecidos em processo de reparação em diferentes estágios evolutivos, que só podem ser diferenciados na análise histopatológica, considerada padrão ouro para esta finalidade. Para esta avaliação, além da medida do espaço do ligamento periodontal, também foi realizada avaliação do infiltrado inflamatório, processo de selamento biológico apical e integridade das superfícies cementárias e ósseas ao redor do ápice. Essas características têm sido estabelecidas e utilizadas por nosso grupo de pesquisa como representativas do sucesso endodôntico do ponto de vista histopatológico (Leonardo et al., 1993; Leonardo et al., 2002, Hidalgo et al., 2016).

$\mathrm{Na}$ literatura, verifica-se que o termo "sucesso endodôntico" tem sido muito utilizado nos últimos anos, porém, os métodos de avaliação clínicos e radiográficos para determinação de sucesso têm sido questionados. Em 1986, The periapical index (ou teste PAI) foi proposto para avaliar lesões periapicais em imagens radiográficas e desenhos comparativos. No entanto, o diagnóstico está baseado no estado dos tecidos periapicais observados apenas radiograficamente. Fazendo a comparação com desenhos de lesões periapicais 
em progressão, realizado pelos autores do escore, determina-se o diagnóstico: raiz com lesão periapical, raiz hígida ou diagnóstico incerto (Orstavik et al., 1986). Contudo, o teste PAI é mundialmente utilizado nas pesquisas sobre periodontite apical e as limitações no diagnóstico radiográfico não acompanhado de avaliação histopatológica constitui motivo fundamental pelo qual o tratamento em sessão única tem sido considerado sucedido (Chhabra et al., 2017; Moreira et al., 2017; Schwendicke e Gostemeyer, 2017; Sevekar e Gowda, 2017). O tratamento de dentes com periodontite apical em sessão única é defendido por profissionais que avaliam o sucesso clínico e radiográfico do tratamento endodôntico, priorizando o conforto do paciente em mínimo tempo de atendimento (Wong et al., 2015; Bharuka e Mandroli, 2016; Fonzar et al., 2017). No presente estudo, embora o tratamento em sessão única tenha reduzido o percentual de área radiolúcida periapical na análise radiográfica, na análise histopatológica verificou-se persistência da resposta inflamatória crônica e reabsorção do ligamento periodontal, cemento e osso alveolar, não havendo reparação tecidual.

A radiografia periapical é a ferramenta mais comumente utilizada para a avaliação da presença de lesão periapical pelos cirurgiões dentistas e especialistas em função do menor custo e menor dose de radiação. No entanto, estudos comparativos entre a radiografia periapical e a tomografia computadorizada tem demonstrado que a tomografia computadorizada possibilita um diagnóstico mais preciso por proporcionar uma imagem tridimensional, que se aproxima mais aos resultados histopatológicos (Paula-Silva et al., 2009; Lemagner et al., 2015; Weissman et al., 2015; Sakdhari et al., 2016). Embora as radiografias periapicais apresentem limitações no diagnóstico em função da sobreposição de imagens (Davies et al., 2015; Lemagner et al., 2015; Weissman et al., 2015; Leonardi Dutra et al., 2016; Sakdhari et al., 2016) esta foi utilizada no presente estudo pois foi acompanhada da avaliação histopatológica que é considerada o padrão ouro para a avaliação da resposta tecidual do hospedeiro.

Um achado importante no presente estudo ocorreu na avaliação do processo de selamento apical dos grupos com novo protocolo e com tratamento em duas sessões com utilização de curativo de demora, permitindo-nos observar 
o processo progressivo de reparo desta região. Estudos prévios têm descrito que o cemento neoformado após processos de reabsorção inflamatória pode ser composto por dois tipos de matrizes, tipo celular e acelular (Bosshardt et al., 1997), em diferentes regiões da estrutura radicular (Ricucci et al., 2014). No presente estudo foi observada deposição de cemento do tipo celular nas áreas extrarradiculares, em lacunas de Howship inativas presentes na superfície externa e interna do cemento residual prosseguindo em continuidade com a deposição de tecido mineralizado verificada nas paredes do canal cementário e forame apical. Ainda foi observado, em etapas de reparo mais avançado, o completo fechamento do forame apical por cemento do tipo celular, com persistência de uma porção central, ainda em processo de mineralização. Em lacunas cementárias internas aumentadas, foi observado o mesmo padrão, sendo que a deposição do cemento foi iniciado na periferia da lacuna e finalizada com o retorno do cementócito. Esses achados sugerem que o selamento apical com tecido mineralizado tem uma orientação centrípeta, iniciando em regiões periféricas até o centro do forame, principalmente formado por cemento de tipo celular. A literatura que caracteriza a natureza do tecido mineralizado depositado no reparo apical após tratamento endodôntico é limitada, sendo o reparo do cemento mais estudado durante o tratamento ortodôntico (Mehta et al., 2017) e tratamento periodontal (Yu et al., 2016; Hernandez-Monjaraz et al., 2018). Assim, é necessário realizar mais pesquisas focadas no papel do cemento no reparo apical e na caracterização da natureza do tecido formado nessa região com técnicas específicas para esta finalidade (como imunoistoquímica ou imunofluorescência), visando favorecer a terapia endodôntica reparadora ou mesmo regenerativa.

A ocorrência de processo de reparo menos avançado nos dentes tratados com o novo protocolo foi verificada pela menor ocorrência de selamento biológico total e pelas características do tecido reparativo cicatricial do ligamento periodontal, que se apresentou menos organizado com delicados feixes de fibras colágenas e poucos vasos sanguíneos neoformados. Esses resultados podem ter decorrido da aplicação da pasta à base de hidróxido de cálcio ter sido limitada à região apical e periapical, restando micro-organismos e seus subprodutos nos 
túbulos dentinários e ramificações dos canais radiculares, que não sofreram ação do curativo de demora, como no grupo controle positivo onde a medicação é mantida por 14 dias no interior do canal radicular, atingindo todo sistema de canais. Considerando que a infecção de dentes com necrose pulpar e lesão periapical encontra-se localizada não apenas na luz do canal radicular principal e túbulos dentinários, mas também em todo o sistema de canais radiculares (Leonardo et al., 2002; Leonardo, 2005; Leonardo et al., 2007; Rocha et al., 2008; Ricucci et al., 2018), sugere-se que este novo protocolo tenha sido mais eficaz no combate à infecção extrarradicular, presente no biofilme periapical. Assim, embora promissor e viável, este novo protocolo poderia ser futuramente associado à uma técnica que seja mais efetiva na eliminação da infecção intrarradicular, presente no sistema de canais radiculares, a exemplo dos sistemas de irrigação por pressão negativa ou ativa ou da terapia fotodinâmica antimicrobiana (aPDT), acompanhados de avaliação de sua eficácia antimicrobiana. 

6. CONCLUSÃO 

Com base nos resultados do presente estudo in vivo, pôde-se concluir que o novo protocolo de tratamento endodôntico, com aplicação de pasta à base de hidróxido de cálcio na região apical e periapical, seguido de obturação na mesma sessão, promoveu reparação tecidual, porém em estágio menos evoluído quando comparado ao tratamento convencional em duas sessões. 

REFERENCIAS

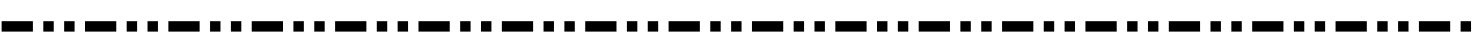



Adl A, Hamedi S, Sedigh Shams M, Motamedifar M, Sobhnamayan F. The ability of triple antibiotic paste and calcium hydroxide in disinfection of dentinal tubules. Iran Endod $\mathrm{J}$. 2014;9(2):123-6.

Adl A, Motamedifar M, Shams MS, Mirzaie A. Clinical investigation of the effect of calcium hydroxide intracanal dressing on bacterial lipopolysaccharide reduction from infected root canals. Aust Endod J. 2015;41(1):12-6.

Adl A, Shojaee NS, Motamedifar M. A Comparison between the Antimicrobial Effects of Triple Antibiotic Paste and Calcium Hydroxide Against Entrococcus Faecalis. Iran Endod $\mathrm{J}$. 2012;7(3):149-55.

Albashaireh ZSM, Alnegrish AS. Postobturation pain after single- and multiple-visit endodontic therapy. A prospective study. J Dent. 1998;26(3):227-32.

Allard U, Stromberg U, Stromberg T. Endodontic treatment of experimentally induced apical periodontitis in dogs. Endod Dent Traumatol. 1987;3(5):240-4.

Andersen M, Lund A, Andreasen JO, Andreasen FM. In vitro solubility of human pulp tissue in calcium hydroxide and sodium hypochlorite. Endod Dent Traumatol. 1992;8(3):104-8.

Archilla JR, Moreira MS, Miyagi SP, Bombana AC, Gutknecht N, Marques MM. Single session of Nd:YAG laser intracanal irradiation neutralizes endotoxin in dental root dentin. J Biomed Opt. 2012;17(11):118002.

Assed S, Ito IY, Leonardo MR, Silva LA, Lopatin DE. Anaerobic microorganisms in root canals of human teeth with chronic apical periodontitis detected by indirect immunofluorescence. Endod Dent Traumatol. 1996;12(2):66-9.

Awawdeh L, Al-Beitawi M, Hammad M. Effectiveness of propolis and calcium hydroxide as a short-term intracanal medicament against Enterococcus faecalis: a laboratory study. Aust Endod J. 2009;35(2):52-8.

Barthel CR, Levin LG, Reisner HM, Trope M. TNF-alpha release in monocytes after exposure to calcium hydroxide treated Escherichia coli LPS. Int Endod J. 1997;30(3):155-9.

Bharuka S, Mandroli P. Single- versus two-visit pulpectomy treatment in primary teeth with apical periodontitis: A double-blind, parallel group, randomized controlled trial. J Indian Soc Pedod Prev Dent. 2016;34(4):383-90.

Borsatto M, Correa-Alfonso A, Lucisano M, Silva RAB, Paula-Silva F, Nelson-Filho P, et al. Onesession root canal treatment with antimicrobial photodynamic therapy (aPDT): an in vivo study. Int Endod J. 2016;49(6):511.

Bosshardt DD, Selvig KA. Dental cementum: the dynamic tissue covering of the root. Periodontol 2000. 1997;13:41-75.

Bystrom A, Claesson R, Sundqvist G. The antibacterial effect of camphorated paramonochlorophenol, camphorated phenol and calcium hydroxide in the treatment of infected root canals. Endod Dent Traumatol. 1985;1(5):170-5.

Byström A, Sundqvist G. Bacteriologic evaluation of the efficacy of mechanical root canal instrumentation in endodontic therapy. Scand J Dent Res. 1981;89(4):321-8.

Bystrom A, Sundqvist G. The antibacterial action of sodium hypochlorite and EDTA in 60 cases of endodontic therapy. Int Endod J. 1985;18(1):35-40. 
Capik I, Sevcikova Z, Ledecky V. Radiological and histological assessment of periapical repair after obturation of infected root canals in dogs. Acta Veterinaria Brno. 2005;74(2):237-242.

Cardoso FG, Chung A, Martinho FC, Camargo CH, Carvalho CA, Gomes BP, et al. Investigation of bacterial contents from persistent endodontic infection and evaluation of their inflammatory potential. Braz Dent J. 2016;27(4):412-8.

Chhabra A, Dogra A, Garg N, Bhatia R, Sharma S, Thakur S. Clinical and radiographic assessment of periapical pathology in single versus multivisit root canal treatment: An in vivo study. J Conserv Dent. 2017;20(6):429-33.

Cohenca N, Romualdo PC, da Silva LAB, da Silva RAB, de Queiroz AM, De Rossi A, et al. Tissue response to root canal irrigation systems in dogs' teeth with apical periodontitis. Clin Oral Investig. 2015;19(5):1147-56.

Cohenca N, Silva LAB, Silva RAB, Nelson-Filho P, Heilborn C, Watanabe $E$, et al. Microbiological evaluation of different irrigation protocols on root canal disinfection in teeth with apical periodontitis: An In Vivo Study. Braz Dent J. 2013;24:467-73.

Cordeiro RCL, Leonardo MR, Silva LAB, Cerri PS. Desenvolvimento de um dispositivo para padronizaçäo de tomadas radiográficas em cäes. RPG, Rev Pós-Grad. 1995;2(3):138-40.

Coser RM, Giro EMA. Tratamento endodôntico de molares decíduos humanos com necrose pulpar e lesão periapical: estudo radiográfico. PGR - Pós-Grad Rev Fac Odontol Sao José dos Campos. 2010;5(1):84-92.

Davies A, Mannocci F, Mitchell P, Andiappan M, Patel S. The detection of periapical pathoses in root filled teeth using single and parallax periapical radiographs versus cone beam computed tomography - a clinical study. Int Endod J. 2015;48(6):582-92.

De Rossi A, Silva LA, Leonardo MR, Rocha LB, Rossi MA. Effect of rotary or manual instrumentation, with or without a calcium hydroxide/1\% chlorhexidine intracanal dressing, on the healing of experimentally induced chronic periapical lesions. Oral Surg Oral Med Oral Pathol Oral Radiol Endod. 2005;99(5):628-36.

Del Carpio-Perochena A, Kishen A, Felitti R, Bhagirath AY, Medapati MR, Lai C, et al. Antibacterial procerties of chitosan nanoparticles and propolis associated with calcium hydroxide against single- and multispecies biofilms: An In Vitro and In Situ Study. J Endod. 2017;43(8):1332-6.

DiRenzo A, Gresla T, Johnson BR, Rogers M, Tucker D, BeGole EA. Postoperative pain after 1- and 2-visit root canal therapy. Oral Surg Oral Med Oral Pathol Oral Radiol Endod. 2002;93(5):605-10.

Donyavi Z, Ghahari P, Esmaeilzadeh M, Kharazifard M, Yousefi-Mashouf R. Antibacterial efficacy of calcium hydroxide and chlorhexidine mixture for treatment of teeth with primary endodontic lesions: a randomized clinical trial. Iran Endod J. 2016;11(4):255-60.

Dotto SR, Travassos RMC, Ferreira R, Santos R, Wagner M. Evaluation of the antimicrobial action of different medications used in endodontics. Odonto Ciência. 2006; 21(53): 262-9.

Estrela C, Decurcio DA, de Alencar AHG, Sydney GB, Silva JA. Efficacy of calcium hydroxide dressing in endodontic infection treatment: a systematic review. Odonto Ciência. 2008;23(1):82-6.

Estrela C, Holland R. Calcium hydroxide: study based on scientific evidences. J Appl Oral Sci. 2003;11(4):269-82. 
Eyuboglu TF, Olcay K, Ozcan M. A clinical study on single-visit root canal retreatments on consecutive 173 patients: frequency of periapical complications and clinical success rate. Clin Oral Investig. 2017;21(5):1761-8.

Ferreira, DCA. Desenvolvimento e caracterização físico-química de um sistema para liberação intracanal de Epigalocatequina-3-galato e seu efeito na cor dos dentes. Ribeirão Preto, 2013. 99p. [Dissertação de Mestrado]. Ribeirão Preto: Faculdade de Odontologica de Ribeirão Preto da Universidade de São Paulo; 2013.

Fonzar F, Mollo A, Venturi M, Pini P, Fabian Fonzar R, Trullenque-Eriksson A, et al. Single versus two visits with 1-week intracanal calcium hydroxide medication for endodontic treatment: One-year post-treatment results from a multicentre randomised controlled trial. Eur J Oral Implantol. 2017;10(1):29-41.

Georgopoulou M, Kontakiotis E, Nakou M. In vitro evaluation of the effectiveness of calcium hydroxide and paramonochlorophenol on anaerobic bacteria from the root canal. Endod Dent Traumatol. 1993;9(6):249-53.

Gomes-Filho JE, Duarte PC, Ervolino E, Mogami Bomfim SR, Xavier Abimussi CJ, Mota da Silva Santos $L$, et al. Histologic characterization of engineered tissues in the canal space of closedapex teeth with apical periodontitis. J Endod. 2013;39(12):1549-56.

Haapasalo M, Orstavik D. In vitro infection and disinfection of dentinal tubules. J Dent Res. 1987;66(8):1375-9.

Hasselgren G, Olsson B, Cvek M. Effects of calcium hydroxide and sodium hypochlorite on the dissolution of necrotic porcine muscle tissue. J Endod. 1988;14(3):125-7.

Heithersay GS. Stimulation of root formation in incompletely developed pulpless teeth. Oral Surg Oral Med Oral Pathol. 1970;29(4):620-30.

Hernandez-Monjaraz B, Santiago-Osorio E, Monroy-Garcia A, Ledesma-Martinez E, MendozaNunez VM. Mesenchymal stem cells of dental origin for inducing tissue regeneration in periodontitis: A mini-review. Int J Mol Sci. 2018;19(4).

Hidalgo LRC, da Silva LAB, Nelson-Filho P, da Silva RAB, de Carvalho FK, Lucisano MP, et al. Comparison between one-session root canal treatment with aPDT and two-session treatment with calcium hydroxide-based antibacterial dressing, in dog's teeth with apical periodontitis. Lasers Medical Sci. 2016;31(7):1481-91.

Holland R. Periapical response to apical plugs of dentin and calcium hydroxide in ferret canines. J Endod. 1984;10: 71-4.

Holland R, de Souza V, de Mello W, Nery MJ, Bernabe PF, Otoboni-Filho JA. Permeability of the hard tissue bridge formed after pulpotomy with calcium hydroxide: a histologic study. J Am Dent Assoc. 1979;99(3):472-5.

Holland R, Nery MJ, Mello W, Souza V, Bernabe PF, Otoboni-Filho JA. Root canal treatment with calcium hydroxide. I. Effect of overfilling and refilling. Oral Surg Oral Med Oral Pathol. $1979 ; 47(1): 87-92$.

Holland R, Souza V, Nery MJ, Bernabe PF, Mello W, Otoboni-Filho JA. Apical hard-tissue deposition in adult teeth of monkeys with use of calcium hydroxide. Aust Dent $\mathrm{J}$. 1980;25(4):189-92. 
Holland R, Souza V, Nery MJ, Mello W, Bernabé PF, Otoboni-Filho JA. A histological study of the effect of calcium hydroxide in the treatment of pulpless teeth of dogs. Int Endod $\mathrm{J}$. 1979;12(1):15-24.

Horiba N, Maekawa Y, Ito M, Matsumoto T, Nakamura H. A pilot study of Japanese green tea as a medicament: antibacterial and bactericidal effects. J Endod. 1991;17(3):122-4.

Huffaker SK, Safavi K, Spangberg LS, Kaufman B. Influence of a passive sonic irrigation system on the elimination of bacteria from root canal systems: a clinical study. J Endod. 2010;36(8):1315-8.

Imura N, Zuolo ML. Factors associated with endodontic flare-ups: a prospective study. Int Endod J. 1995;28(5):261-5.

Jafari F, Aghazadeh M, Jafari S, Khaki F, Kabiri F. In vitro cytotoxicity comparison of MTA fillapex, AH-26 and apatite root canal sealer at different setting times. Iran Endod J. 2017;12(2):162-7.

Jafari F, Samadi Kafil H, Jafari S, Aghazadeh M, Momeni T. Antibacterial activity of MTA Fillapex and $\mathrm{AH} 26$ root canal sealers at different time intervals. Iran Endod $\mathrm{J}$. 2016;11(3):192-7.

Kakehashi S, Stanley HR, Fitzgerald RJ. The effects of surgical exposures of dental pulps in germ-free and conventional laboratory rats. Oral Surg Oral Med Oral Pathol. 1965;20:340-9.

Lakhani AA, Sekhar KS, Gupta P, Tejolatha B, Gupta A, Kashyap S, et al. Efficacy of triple antibiotic paste, moxifloxacin, calcium hydroxide and $2 \%$ chlorhexidine gel in elimination of E. Faecalis: an in vitro study. J Clin Diagn Res. 2017;11(1):6-9.

Lee $\mathrm{YL}$, Hong $\mathrm{CY}$, Kok $\mathrm{SH}$, Hou KL, Lin $\mathrm{YT}$, Chen $\mathrm{MH}$, et al. An extract of green tea, epigallocatechin-3-gallate, reduces periapical lesions by inhibiting cysteine-rich 61 expression in osteoblasts. J Endod. 2009;35(2):206-11.

Lemagner F, Maret D, Peters OA, Arias A, Coudrais E, Georgelin-Gurgel M. Prevalence of apical bone defects and evaluation of associated factors detected with cone-beam computed tomographic images. J Endod. 2015;41(7):1043-7.

Leonardi-Dutra K, Haas L, Porporatti AL, Flores-Mir C, Nascimento Santos J, Mezzomo LA, Corrêa M, De Luca-Canto G. Diagnostic accuracy of cone-beam computed tomography and conventional radiography on apical periodontitis: a systematic review and meta-analysis. J Endod. 2016;42(3):356-64.

Leonardo M. Preparo biomecânico dos canais radiculares In: Leonardo M (ed). Endodontia: tratamento de canais radiculares: princípios técnicos e biológicos. São Paulo: Artes Médicas; 2005. p. 450.

Leonardo MR, Almeida WA, Silva LAB, Utrilla LS. Histopathological observations of periapical repair in teeth with radiolucent areas submitted to 2 different methods of root-canal treatment. J Endod. 1995;21(3):137-41.

Leonardo MR, da Silva LA, Leonardo RT, Utrilla LS, Assed S. Histological evaluation of therapy using a calcium hydroxide dressing for teeth with incompletely formed apices and periapical lesions. J Endod. 1993; 19(7):348-52.

Leonardo MR, Silva LAB, Filho MT, Bonifácio KC, Ito IY. In Vitro Evaluation of Antimicrobial Activity of Sealers and Pastes Used in Endodontics. J Endod. 2000;26(7):391-4. 
Leonardo MR, Hernandez ME, Silva LA, Tanomaru-Filho M. Effect of a calcium hydroxidebased root canal dressing on periapical repair in dogs: a histological study. Oral Surg Oral Med Oral Pathol Oral Radiol Endod. 2006;102(5):680-5.

Leonardo MR, Rossi MA, Bonifácio KC, Silva LAB, Assed S. Scanning Electron Microscopy of the Apical Structure of Human Teeth. Ultrastruct Pathol. 2007;31(4):321-5.

Leonardo MR, Silva RA, Assed S, Nelson-Filho P. Importance of bacterial endotoxin (LPS) in endodontics. J Appl Oral Sci. 2004;12(2):93-8.

Leonardo MR, Silveira FF, Silva LA, Tanomaru Filho M, Utrilla LS. Calcium hydroxide root canal dressing. Histopathological evaluation of periapical repair at different time periods. Braz Dent J. 2002;13(1):17-22.

Madhubala MM, Srinivasan N, Ahamed S. Comparative evaluation of propolis and triantibiotic mixture as an intracanal medicament against Enterococcus faecalis. J Endod. 2011;37(9):1287-9.

Manfredi M, Figini L, Gagliani M, Lodi G. Single versus multiple visits for endodontic treatment of permanent teeth. Cochrane Database Syst Rev. 2016;12:5296.

Massara M. A eficácia do hidróxido de cálcio no tratamento endodôntico de decíduos: seis anos de avaliação. Pesq Bras Odontoped Clin Integr, Joao Pessoa. 2012;12(2):155-9.

Mehta SA, Deshmukh SV, Sable RB, Patil AS. Comparison of 4 and 6 weeks of rest period for repair of root resorption. Prog Orthod. 2017;18(1):18.

Molander A, Reit C, Dahlen G, Kvist T. Microbiological status of root-filled teeth with apical periodontitis. Int Endod J. 1998;31(1):1-7.

Molander A, Warfvinge J, Reit C, Kvist T. Clinical and radiographic evaluation of one- and two-visit endodontic treatment of asymptomatic necrotic teeth with apical periodontitis: a randomized clinical trial. J Endod. 2007;33(10):1145-8.

Moreira MS, Anuar ASN, Tedesco TK, Dos Santos M, Morimoto S. Endodontic treatment in single and multiple visits: an overview of systematic reviews. J Endod. 2017;43(6):864-70.

Nair PN, Sjogren U, Figdor D, Sundqvist G. Persistent periapical radiolucencies of root-filled human teeth, failed endodontic treatments, and periapical scars. Oral Surg Oral Med Oral Pathol Oral Radiol Endod. 1999;87(5):617-27.

Nair PN, Sjogren U, Krey G, Kahnberg KE, Sundqvist G. Intraradicular bacteria and fungi in root-filled, asymptomatic human teeth with therapy-resistant periapical lesions: a long-term light and electron microscopic follow-up study. J Endod. 1990;16(12):580-8.

Nelson Filho P, Silva LA, Leonardo MR, Utrilla LS, Figueiredo F. Connective tissue responses to calcium hydroxide-based root canal medicaments. Int Endod J. 1999;32(4):303-11.

Nelson-Filho P, Leonardo MR, Assed Bezerra Silva L, Assed S. Radiographic evaluation of the effect of endotoxin (LPS) plus calcium hydroxide on apical and periapical tissues of dogs. J Endod. 2002;28(10):694-6.

Nobrega LM, Montagner F, Ribeiro AC, Mayer MA, Gomes BP. Bacterial diversity of symptomatic primary endodontic infection by clonal analysis. Braz Oral Res. 2016;30(1):103. 
Oliveira LD, Jorge AO, Carvalho CA, Koga-Ito CY, Valera MC. In vitro effects of endodontic irrigants on endotoxins in root canals. Oral Surg Oral Med Oral Pathol Oral Radiol Endod. 2007;104(1):135-42.

Oliveira LD, Leao MV, Carvalho CA, Camargo $\mathrm{CH}$, Valera MC, Jorge AO, et al. In vitro effects of calcium hydroxide and polymyxin B on endotoxins in root canals. J Dent. 2005;33(2):10714.

Orstavik D, Kerekes K, Eriksen HM. The periapical index: a scoring system for radiographic assessment of apical periodontitis. Endod Dent Traumatol. 1986;2(1):20-34.

Pai S, Vivekananda Pai AR, Thomas MS, Bhat V. Effect of calcium hydroxide and triple antibiotic paste as intracanal medicaments on the incidence of inter-appointment flare-up in diabetic patients: An in vivo study. J Conserv Dent. 2014;17(3):208-11.

Paiva SS, Siqueira JF, Jr., Rocas IN, Carmo FL, Leite DC, Ferreira DC, et al. Molecular microbiological evaluation of passive ultrasonic activation as a supplementary disinfecting step: a clinical study. J Endod. 2013;39(2):190-4.

Paredes-Vieyra J, Enriquez FJ. Success rate of single- versus two-visit root canal treatment of teeth with apical periodontitis: a randomized controlled trial. J Endod. 2012;38(9):1164-9.

Patil AA, Joshi SB, Bhagwat SV, Patil SA. Incidence of postoperative pain after single visit and two visit root canal therapy: a randomized controlled trial. J Clin Diagn Res. 2016;10(5):Zc0912.

Paula-Silva FW, Wu MK, Leonardo MR, da Silva LA, Wesselink PR. Accuracy of periapical radiography and cone-beam computed tomography scans in diagnosing apical periodontitis using histopathological findings as a gold standard. J Endod. 2009;35:1009-12.

Pawar R, Alqaied A, Safavi K, Boyko J, Kaufman B. Influence of an apical negative pressure irrigation system on bacterial elimination during endodontic therapy: a prospective randomized clinical study. J Endod. 2012;38(9):1177-81.

Penesis VA, Fitzgerald PI, Fayad MI, Wenckus CS, BeGole EA, Johnson BR. Outcome of onevisit and two-visit endodontic treatment of necrotic teeth with apical periodontitis: a randomized controlled trial with one-year evaluation. J Endod. 2008;34(3):251-7.

Pereira RS, Rodrigues VAA, Furtado WT, Gueiros S, Pereira GS, Avila-Campos MJ. Microbial analysis of root canal and periradicular lesion associated to teeth with endodontic failure. Anaerobe. 2017;48:12-8.

Pirani C, Chersoni S, Montebugnoli L, Prati C. Long-term outcome of non-surgical root canal treatment: a retrospective analysis. Odontology. 2015;103(2):185-93.

Pirani C, Friedman S, Gatto MR, Iacono F, Tinarelli V, Gandolfi MG, et al. Survival and periapical health after root canal treatment with carrier-based root fillings: five-year retrospective assessment. Int Endod J. 2018;51:178-88.

Pitts $\mathrm{DL}$, Jones JE, Oswald RJ. A histological comparison of calcium hydroxide plugs and dentin plugs used for the control of Gutta-percha root canal filling material. J Endod. 1984;10(7):283-93.

Qualtrough AJ, Whitworth JM, Dummer PM. Preclinical endodontology: an international comparison. Int Endod J. 1999;32(5):406-14. 
Queiroz AM, Arid J, Nelson-Filho P, Lucisano MP, Silva RA, Sorgi CA, Faccioli LH, Silva LAB. Correlation between bacterial endotoxin levels in root canals of primary teeth and the periapical lesion area. J Dent Child. 2016;83(1):9-15.

Rabello DGD, Corazza BJM, Ferreira LL, Santamaria MP, Gomes APM, Martinho FC. Does supplemental photodynamic therapy optimize the disinfection of bacteria and endotoxins in one-visit and two-visit root canal therapy? A randomized clinical trial. Photodiagnosis Photodyn Ther. 2017;19:205-11.

Ramezanali F, Samimi S, Kharazifard M, Afkhami F. The in vitro antibacterial efficacy of persian green tea extract as an intracanal irrigant on enterococcus faecalis biofilm. Iran Endod J. $2016 ; 11(4): 304-8$.

Rao KN, Kandaswamy R, Umashetty G, Rathore VP, Hotkar C, Patil BS. Post-Obturation pain following one-visit and two-visit root canal treatment in necrotic anterior teeth. J Int Oral Health. 2014;6(2):28-32.

Rezende GP, da Costa LR, Pimenta FC, Baroni DA. In vitro antimicrobial activity of endodontic pastes with propolis extracts and calcium hydroxide: a preliminary study. Braz Dent $\mathrm{J}$. 2008;19(4):301-5.

Rico-Romano C, Zubizarreta-Macho A, Baquero-Artigao MR, Mena-Alvarez J. An analysis in vivo of intracanal bacterial load before and after chemo-mechanical preparation: A comparative analysis of two irrigants and two activation techniques. J Clin Exp Dent. 2016;8(1):9-13.

Ricucci D, Loghin S, Goncalves LS, Rocas IN, Siqueira JF, Jr. Histobacteriologic conditions of the apical root canal system and periapical tissues in teeth associated with sinus tracts. J Endod. 2018;44(3):405-13.

Ricucci D, Siqueira JF, Jr., Loghin S, Lin LM. Repair of extensive apical root resorption associated with apical periodontitis: radiographic and histologic observations after 25 years. J Endod. 2014;40(8):1268-74.

Ricucci D, Siqueira JF, Jr., Lopes WS, Vieira AR, Rocas IN. Extraradicular infection as the cause of persistent symptoms: a case series. J Endod. 2015;41(2):265-73.

Rietschel ET, Brade H. Bacterial endotoxins. Sci Am. 1992;267(2):54-61.

Rocha CT, Rossi MA, Leonardo MR, Rocha LB, Nelson-Filho P, Silva LA. Biofilm on the apical region of roots in primary teeth with vital and necrotic pulps with or without radiographically evident apical pathosis. Int Endod J. 2008;41(8):664-9.

Safavi KE, Nichols FC. Alteration of biological properties of bacterial lipopolysaccharide by calcium hydroxide treatment. J Endod. 1994;20(3):127-9.

Sakhdari S, Talaeipour AR, Talaeipour M, Pazhutan M, Tehrani SH, Kharazifard MJ. Diagnostic accuracy of CBCT with different voxel sizes and intraoral digital radiography for detection of periapical bone lesions: An ex-vivo study. J Dent (Tehran). 2016;13(2):77-84.

Sathorn C, Parashos P, Messer HH. Effectiveness of single- versus multiple-visit endodontic treatment of teeth with apical periodontitis: a systematic review and meta-analysis. Int Endod J. 2005;38(6):347-55.

Savani GM, Sabbah W, Sedgley CM, Whitten B. Current trends in endodontic treatment by general dental practitioners: report of a United States national survey. J Endod. 2014;40(5):618-24. 
Schroder U. Effects of calcium hydroxide-containing pulp-capping agents on pulp cell migration, proliferation, and differentiation. J Dent Res. 1985;64:541-8.

Schwendicke F, Gostemeyer G. Single-visit or multiple-visit root canal treatment: systematic review, meta-analysis and trial sequential analysis. BMJ Open. 2017;7(2):13115.

Sevekar SA, Gowda SHN. Postoperative pain and flare-Ups: comparison of incidence between single and multiple visit pulpectomy in primary molars. J Clin Diagn Res. 2017;11(3):9-12.

Signoretti FG, Endo MS, Gomes BP, Montagner F, Tosello FB, Jacinto RC. Persistent extraradicular infection in root-filled asymptomatic human tooth: scanning electron microscopic analysis and microbial investigation after apical microsurgery. J Endod. 2011;37:1696-700.

Silva LA, Paula-Silva FW, Leonardo MR, Assed S. Radiographic evaluation of pulpal and periapical response of dogs' teeth after pulpotomy and use of recombinant human bone morphogenetic protein-7 as a capping agent. J Dent Child (Chic). 2008;75(1):14-9.

Silva LA, Novaes AB, Jr., de Oliveira RR, Nelson-Filho P, Santamaria M, Jr., Silva RA. Antimicrobial photodynamic therapy for the treatment of teeth with apical periodontitis: a histopathological evaluation. J Endod. 2012;38(3):360-6.

Silva LAB, Nelson-Filho P, Leonardo MR, Rossi MA, Pansani CA. Effect of calcium hydroxide on bacterial endotoxin in vivo. J Endod. 2002;28(2):94-8.

Silva RA, Assed S, Nelson-Filho P, Silva LA, Consolaro A. Subcutaneous tissue response of isogenic mice to calcium hydroxide-based pastes with chlorhexidine. Braz Dent J. 2009;20:99106.

Silva LA, Silva RA, Nelson-Filho P, Cohenca N. Intracanal medication in root canal disinfection. In: Cohenca $N$ (ed). Disinfection of root canal systems: the treatment of apical periodontitis. Seattle: Wiley Blackwell; 2014. p. 247.

Silva RA, Leonardo MR, da Silva LA, de Castro LM, Rosa AL, de Oliveira PT. Effects of the association between a calcium hydroxide paste and $0.4 \%$ chlorhexidine on the development of the osteogenic phenotype in vitro. J Endod. 2008;34(12):1485-9.

Singh S, Garg A. Incidence of post-operative pain after single visit and multiple visit root canal treatment: A randomized controlled trial. J Conserv Dent. 2012;15(4):323-7.

Siqueira JF, Alves FR, Rôças IN. Pyrosequencing analysis of the apical root canal microbiota. Journal of endodontics. 2011;37(11):1499-503.

Siqueira JF, Jr., Antunes HS, Rocas IN, Rachid CT, Alves FR. Microbiome in the apical root canal system of teeth with post-treatment apical periodontitis. PLoS One. 2016;11(9):162887.

Siqueira JF, Jr., Guimaraes-Pinto T, Rocas IN. Effects of chemomechanical preparation with $2.5 \%$ sodium hypochlorite and intracanal medication with calcium hydroxide on cultivable bacteria in infected root canals. J Endod. 2007;33(7):800-5.

Siqueira JF, Jr., Rocas IN. Polymerase chain reaction-based analysis of microorganisms associated with failed endodontic treatment. Oral Surg Oral Med Oral Pathol Oral Radiol Endod. 2004;97(1):85-94.

Sjögren $U$, Figdor $D$, Persson S, Sundqvist G. Influence of infection at the time of root filling on the outcome of endodontic treatment of teeth with apical periodontitis. Int Endod $\mathrm{J}$. 1997;30(5):297-306. 
Sjögren U, Figdor D, Spângberg L, Sundqvist G. The antimicrobial effect of calcium hydroxide as a short-term intracanal dressing. 1991;24:119-25.

Soares JA, César CAS. Avaliação clínica e radiográfica do tratamento endodôntico em sessão única de dentes com lesões periapicais crônicas. Pesquisa Odontológica Brasileira. 2001;15:138-44.

Souza-Gugelmin M, Lima S, Lima C, Jacobovitz M, Ito I. Biossegurança: controle da infecção na Odontologia. In: Leonardo $\mathrm{M}$, editor. Endodontia: tratamento de canais radiculares: princípios técnicos e biológicos. São Paulo: Artes Médicas; 2005. p. 365-406.

Spångberg LS. Evidence-based endodontics: the one-visit treatment idea. Oral Surgery, Oral Medicine, Oral Pathology, Oral Radiology and Endodontology. 2001;6(91):617-8.

Staehle HJ, Thomas C, Muller HP. Comparative in vitro investigation of different methods for temporary root canal filling with aqueous suspensions of calcium hydroxide. Endod Dent Traumatol. 1997;13(3):106-12.

Tani-Ishii N, Wang CY, Tanner A, Stashenko P. Changes in root canal microbiota during the development of rat periapical lesions. Oral Microbiol Immunol. 1994;9(3):129-35.

Tanomaru JM, Leonardo MR, Tanomaru Filho M, Bonetti Filho I, Silva LA. Effect of different irrigation solutions and calcium hydroxide on bacterial LPS. Int Endod J. 2003;36(11):733-9.

Tanomaru JM, Leonardo MR, Tanomaru-Filho M, da Silva LA, Ito IY. Microbial distribution in the root canal system after periapical lesion induction using different methods. Braz Dent J. 2008;19(2):124-9.

Tronstad L. Recent development of endodontic research. J Oral Sci. 1992;100:52 - 9.

Vera J, Siqueira JF, Jr., Ricucci D, Loghin S, Fernandez N, Flores B, et al. One- versus twovisit endodontic treatment of teeth with apical periodontitis: a histobacteriologic study. J Endod. 2012;38(8):1040-52.

Walton R, Fouad A. Endodontic interappointment flare-ups: a prospective study of incidence and related factors. J Endod. 1992;18(4):172-7.

Wang C, Xu P, Ren L, Dong G, Ye L. Comparison of post-obturation pain experience following one-visit and two-visit root canal treatment on teeth with vital pulps: a randomized controlled trial. Int Endod J. 2010;43(8):692-7.

Weissman J, Johnson JD, Anderson M, Hollender L, Huson T, Paranjpe A, et al. Association between the Presence of Apical Periodontitis and Clinical Symptoms in Endodontic Patients Using Cone-beam Computed Tomography and Periapical Radiographs. J Endod. 2015;41(11):1824-9.

Whitten BH, Gardiner DL, Jeansonne BG, Lemon RR. Current trends in endodontic treatment: report of a national survey. J Am Dent Assoc. 1996;127(9):1333-41.

Wong AW, Tsang CS, Zhang S, Li KY, Zhang C, Chu CH. Treatment outcomes of single-visit versus multiple-visit non-surgical endodontic therapy: a randomised clinical trial. BMC Oral Health. 2015;15:162.

Wong AW, Zhang S, Zhang CF, Chu CH. Perceptions of single-visit and multiple-visit endodontic treatment: a survey of endodontic specialists and general dentists in Hong Kong. J Investig Clin Dent. 2015;1:1-9. 
Yu SJ, Lee DS, Kim BO, Choi SH, Park JC. Periodontal healing with a preameloblastconditioned medium in dogs. J Periodontal Res. 2016;51(3):284-94.

Zarei M, Javidi M, Gharechahi M, Kateb M, Zare R, Kelagari ZS. Tissue reaction to different types of calcium hydroxide paste. Bull Tokyo Dent Coll. 2016;57(2):57-64. 
ANEXO 



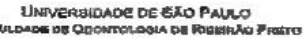

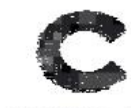

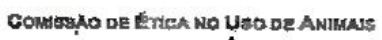

!
Universidade de São PaUlo

Faculdade de Odontologia de Ribeirão Preto COMISSÃo dE ÉTICA NO USO DE ANIMAIS

\section{Certificado ceUa - ForP/USP}

Certificamos que o Protocolo $n^{0} 2014.1,703.58 .9$ sobre a pesquisa intitulada "Avaliação do reparo de lesões periapicals de dentes de cães após diferentes modalidades de tratamento, em úniç ou múltipla sessăo. Estudo radiográfico o histopatológico", sob a responsabilidade da Profa. Dra. Léa Assed Bezerra da Silva, está e acordo com os Principios Étlcos na Experimentaçăo Animal adotados pela Comissão de Ética no Uso de Animais da Faculdade de Odontologia de Ribeirão Preto, USP, foi APROVADO em reuniâa da CEUA de 17/09/2014 (totalizando 3 animais).

We hereby certify that the protocol $n^{\circ} 2014.1 .703 .58 .9$ regarding the research entitled "Evaluation of repair of periapical lesions of dog's teeth after different treatment modalities in single or multiple sessions. Radiographic and histopathologic study", under the responsibility of Profa. Dra. Léa Assed Bezerra da Silva, is in accordance with the Ethical principles in animal research adopted by the Animal Research Ethics Committee of the Scheol of Dentistry of Ribeirão Preto, University of Säo Paulo, Brazil, and was approved in 17/09/2014 (totalizing 3 animals).

Ribeirão Preto, 17 de setembro de 2014.

Profa. Dra-Andiara De Rossi Daldegan

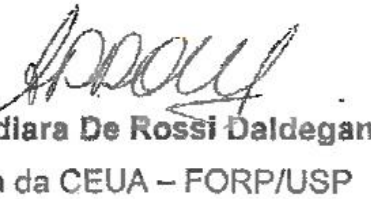

$\because$ Coordenadora da CEUA - FORP/USP

CEUA - FORP/USP 